\title{
Tumor bud-derived CCL5 recruits fibroblasts and promotes colorectal cancer progression via CCR5-SLC25A24 signaling
}

Ling-Fang Gao ${ }^{1,2}$, Yan Zhong ${ }^{1}$, Ting Long ${ }^{1}$, Xia Wang ${ }^{2}$, Jia-Xian Zhu' ${ }^{1}$, Xiao-Yan Wang ${ }^{2,3}$, Zhi-Yan Hu Li, $^{2,3}$ and Zu-Guo Li $\mathrm{il}^{1,2^{*}}$

\begin{abstract}
Background: Tumor budding is included in the routine diagnosis of colorectal cancer (CRC) and is considered a tumor prognostic factor independent of TNM staging. This study aimed to identify the fibroblast-mediated effect of tumor bud-derived C-C chemokine ligand 5 (CCL5) on the tumor microenvironment (TME).

Methods: Recruitment assays and a human cytokine array were used to detect the main cytokines that CRC tumor buds secrete to recruit fibroblasts. siRNA transfection and inhibitor treatment were used to investigate the role of fibroblast CCL5 receptors in fibroblast recruitment. Subsequently, transcriptome sequencing was performed to explore the molecular changes occurring in fibroblasts upon stimulation with CCL5. Finally, clinical specimens and orthotopic xenograft mouse models were studied to explore the contribution of CCL5 to angiogenesis and collagen synthesis.

Results: Hematoxylin-eosin staining and immunochemistry revealed a higher number of fibroblasts at the invasive front of CRC tissue showing tumor budding than at sites without tumor budding. In vitro experiments demonstrated that CCL5 derived from tumor buds could recruit fibroblasts by acting on the CCR5 receptors on fibroblasts. Tumor bud-derived CCL5 could also positively regulate solute carrier family 25 member 24 (SLC25A24) expression in fibroblasts, potentially activating pAkt-pmTOR signaling. Moreover, CCL5 could increase the number of a-SMA ${ }^{\text {high }}$ CD90 ${ }^{\text {high }}$ FAP ${ }^{\text {low }}$ fibroblasts and thus promote tumor angiogenesis by enhancing VEGFA expression and making fibroblasts transdifferentiate into vascular endothelial cells. Finally, the results also showed that CCL5 could promote collagen synthesis through fibroblasts, thus contributing to tumor progression.
\end{abstract}

Conclusions: At the invasive front of CRC, tumor bud-derived CCL5 can recruit fibroblasts via CCR5-SLC25A24 signaling, further promoting angiogenesis and collagen synthesis via recruited fibroblasts, and eventually create a tumorpromoting microenvironment. Therefore, CCL5 may serve as a potential diagnostic marker and therapeutic target for tumor budding in CRC.

Keywords: Tumor budding, CCL5, Fibroblast, Colorectal cancer, CCR5, SLC25A24, Angiogenesis, Collagen synthesis

*Correspondence: lizg@smu.edu.cn

${ }^{1}$ Department of Pathology, Shenzhen Hospital, Southern Medical University, Shenzhen 518101, Guangdong, China

Full list of author information is available at the end of the article

\section{Background}

The relationship between tumors and the tumor microenvironment (TME) is analogous to that between seeds and the soil. Studies are gradually focusing not only on the tumor alone but also on the TME. Cancerassociated fibroblasts (CAFs), an indispensable part of original author(s) and the source, provide a link to the Creative Commons licence, and indicate if changes were made. The images or other third party material in this article are included in the article's Creative Commons licence, unless indicated otherwise in a credit line to the material. If material is not included in the article's Creative Commons licence and your intended use is not permitted by statutory regulation or exceeds the permitted use, you will need to obtain permission directly from the copyright holder. To view a copy of this licence, visit http://creativecommons.org/licenses/by/4.0/. The Creative Commons Public Domain Dedication waiver (http://creativeco mmons.org/publicdomain/zero/1.0/) applies to the data made available in this article, unless otherwise stated in a credit line to the data. 
the tumor stroma, have attracted increasing attention in recent years [1-3]. Evidence from both clinical and basic studies has revealed a strong association between the number of CAFs and poor clinical outcomes in several types of cancer, including breast cancer [4], cervical cancer [5], lung cancer [6], cholangiocarcinoma [7], and colorectal cancer (CRC) [8, 9]. The crosstalk between fibroblasts and tumor cells can lead to fibroblast activation, subsequently resulting in tumor metastasis [8], treatment resistance [10], and immunosuppression [11]. However, the mechanism underlying the initial transformation of fibroblasts to a tumor-promoting state remains unclear.

Tumor budding in CRC is defined as a single tumor cell or a cell cluster of up to four tumor cells, assessed in one hotspot (in a field measuring $0.785 \mathrm{~mm}^{2}$ ) at the invasive front $[12,13]$. Studies have indicated a close link between tumor budding and a distinctive immune-suppressing microenvironment that promotes tumor invasion in gastric adenocarcinoma [14], stage I lung adenocarcinoma [15], pancreatic cancer [16], and CRC [17]. Nevertheless, the crosstalk between fibroblasts and tumor buds, and the mechanism through which the crosstalk occurs remain unknown.

$\mathrm{C}-\mathrm{C}$ chemokine ligand 5 (CCL5), also known as Regulated upon Activation, Normal T-cell Expressed, and Secreted (RANTES), interacts with the G-protein-coupled receptors CCR1, CCR3, CCR4, CCR5, GPR75, and CD44 $[18,19]$. CCL5 is expressed in T lymphocytes, macrophages, platelets, synovial fibroblasts, the tubular epithelia, and tumor cells [20]. As a chemokine, CCL5 plays an active role in recruiting a variety of leukocytes to sites of inflammation. In CRC, macrophage-derived CCL5 facilitates the immune escape of cancer cells via the p65/STAT3-CSN5-PD-L1 pathway [21]. Moreover, tumor-derived CCL5 enhances TGF- $\beta$ secretion in T regulatory cells via the CCL5/CCR 5 axis, thereby blocking the killing function of $\mathrm{CD}^{+} \mathrm{T}$ cells [22]. Nevertheless, the biological effect of tumor-derived CCL5 on fibroblasts remains elusive. Moreover, fibroblasts have also been recognized as an important source of CCL5 [23-25], and whether human colorectal fibroblasts influence themselves through CCL5 autocrine function remains to be explored.

Here, we report for the first time that CCL5 secreted by CRC tumor buds at the invasive front can recruit surrounding fibroblasts through the CCR5-solute carrier family 25 member 24 (SLC25A24) pathway, and further promote CRC progression via fibroblast-mediated increases in angiogenesis and collagen synthesis. These findings show that CCL5 may serve as a potential diagnostic marker and therapeutic target for tumor budding in CRC.

\section{Methods}

Antibodies, small interfering RNA (siRNA), and primer sequences

The primary antibodies used in the study are summarized in Additional file 6: Table S1. The siRNA and primer sequences used in the study are summarized in Additional file 7: Table S2 and Additional file 8: Table S3 respectively.

\section{Cell lines and cell culture}

The human CRC cell lines LS174T (CL-188), RKO (CRL-2577), DLD-1 (CCL-221), Caco2 (HTB-37), SW620 (CCL-227), HCT-8 (CCL-244), HCT116 (CCL247), and HCT-15 (CCL-225); the human normal colorectal epithelial cell line FHC (CRL-1831); and the human normal colorectal fibroblast cell line CCD18Co (CRL-1459) were all purchased from the American Type Culture Collection (ATCC). All human CRC cells were cultured in RPMI-1640 medium (Gibco, C11875500BT) supplemented with 10\% fetal bovine serum (FBS) (ExCell Bio, FND500). FHC was cultured in RPMI-1640 medium supplemented with $15 \%$ FBS, and CCD-18Co was cultured in Eagle's Minimum Essential Medium (EMEM) (ATCC, 30-2003) supplemented with $10 \%$ FBS. All cells were cultured at $37^{\circ} \mathrm{C}$ in humidified atmosphere containing $5 \% \mathrm{CO}_{2}$. Cell line certificates of analysis were obtained from the ATCC. All cell lines were negative for mycoplasma.

\section{Primary normal colorectal fibroblasts: extraction and culture}

Fresh human normal colorectal mucosae were cut using surgical scissors and then enzymatically dissociated in a mixture of type IV collagenase $(2.0 \mathrm{mg} / \mathrm{ml}$, Sigma, C5138), hyaluronidase $(0.4 \mathrm{mg} / \mathrm{ml}$, Sigma, H1115000) and DNase (25 U/ml, Solarbio, D8071) at a constant temperature of $37^{\circ} \mathrm{C}$ for $2 \mathrm{~h}$. The tissues were then passed through a $40-\mu \mathrm{m}$ cell strainer to generate a single-cell suspension. The cell suspensions were centrifuged at $300 \times g$ for $12 \mathrm{~min}$; the supernatant was discarded, and the cell pellet was resuspended in EMEM. Primary cells were then plated at a density of $1 \times 10^{5}$ viable cells in $25 \mathrm{~cm}^{2}$ adherent flasks and cultured at $37{ }^{\circ} \mathrm{C}$ in EMEM with $10 \% \mathrm{FBS}$ in humidified atmosphere containing $5 \%$ $\mathrm{CO}_{2}$ (enzyme digestion method). The tissues that could not pass through the strainer were transferred to $25 \mathrm{~cm}^{2}$ adherent flasks. EMEM supplemented with 10\% FBS was added to the adherent flasks after $24 \mathrm{~h}$, when the tissues had stuck to the bottom. The tissues were incubated until fibroblasts crawled out of them (improved tissue planting method). 


\section{Clinical specimens}

Clinical CRC specimens were obtained from patients who were pathologically diagnosed with CRC at Shenzhen Hospital, Southern Medical University. The study was approved by the ethics committee of Shenzhen Hospital, Southern Medical University, China.

\section{Identification and quantification of tumor budding}

Tumor budding was identified based on the presence of a single tumor cell or a tumor cell cluster of up to 4 cells at the invasive front of CRC tumors. The quantification of tumor budding was performed according to five procedures proposed by the International Tumor Budding Consensus Conference (ITBCC) 2016 for reporting tumor budding in CRC during daily diagnostic practice [13].

\section{Immunohistochemistry (IHC)}

IHC was performed using paraffin-embedded sections of human CRC tissue following the standard LSAB protocol (Dako). Primary antibodies against $\alpha$-SMA, CD90, FAP, CCL5, SLC25A24, CD31, and VEGFA were used for IHC. The degree of staining was observed and scored independently by three pathologists. The percent positivity of CCL5 staining was scored from 0 to 4 , as follows: $0(<5 \%), 1$ (5-25\%), 2 (26-50\%), 3 (51$75 \%)$, and $4(>75 \%)$. The staining intensity was scored on a 4-point scale, as follows: 0 (no staining), 1 (weak staining, light yellow), 2 (moderate staining, yellowish brown), and 3 (strong staining, brown). Subsequently, the CCL5 expression score was calculated by multiplying the percent positivity score with the staining intensity score. Accordingly, the expression of CCL5 was classified as low (0-4), medium (5-8), or high (9-12).

\section{Immunofluorescence (IF) analysis of cells and CRC tissue}

IF analysis of cells was performed as previously described [26]. For IF analysis of CRC tissue, the steps before primary antibody incubation were the same as those used for IHC. The steps after primary antibody incubation were the same as those used for IF analysis of cells. Images of cells were acquired using a laser scanning confocal microscope (Olympus, Japan), and images of CRC tissue were acquired using a fluorescence microscope (Olympus, Japan).

\section{Recruitment assay}

Boyden transwell chambers (Corning, 353,097) were used according to manufacturer's instructions. Briefly, $2 \times 10^{4}$ fibroblasts were added to the upper chambers. The lower chamber contained of the following: $1 \times 10^{5}$ human CRC tumor cells, different concentrations of human CCL5 (Peprotech, 300-06-20), or the conditioned medium (CM) samples from stable CRC cell lines. After $48 \mathrm{~h}$ of incubation, fibroblasts that successfully migrated to the lower chamber were fixed with $4 \%$ paraformaldehyde and stained with hematoxylin. The number of cells was counted in five random visual fields using a light microscope (Olympus, Japan).

\section{Human cytokine array}

Serum-free CM samples from FHC and the human CRC tumor cell lines HCT-8, HCT116, HCT-15, and SW620 were collected after incubation for $24 \mathrm{~h}$ and filtered through a $0.22-\mu \mathrm{m}$ mesh. The CM samples were added to arrays containing antibodies against 1000 unique cytokines (RayBio, GSH-CAA-X00) and processed according to manufacturer's instructions.

\section{RNA extraction and quantitative reverse transcription polymerase chain reaction (qRT-PCR)}

Total cellular mRNA was extracted using the TRIzol reagent (TaKaRa, 9109). The Prime-Script RT Reagent Kit with gDNA Eraser (TaKaRa, D6110A) was used to reverse-transcribe mRNA into cDNA. Finally, the SYBR Premix Ex Taq (TaKaRa, RR420) and the Applied Biosystems $^{\mathrm{TM}} 7500$ Fast Real-Time PCR System (Thermo Fisher, USA) were used for qRT-PCR. All mRNA levels were normalized based on GAPDH levels, and the $2^{-\Delta \Delta \mathrm{Ct}}$ method was used.

\section{Enzyme-linked immunosorbent assay (ELISA)}

CCL5 supernatant levels in the CM samples from FHC and human CRC tumor cells were measured with ELISA using a commercially available kit (CUSABIO, CSBE17375h), as described by the manufacturer's instructions. The results were expressed in $\mathrm{pg} / \mathrm{ml}$, and the standard curve was based on the measured OD values of the standard.

\section{siRNA transfection}

siRNAs for human CCL5, CCR1, CCR3, CCR4, CCR5, CD44, GPR75, and SLC25A24 were purchased from GenePharma (Suzhou, China). HCT-8, SW620, CCD$18 \mathrm{Co}$, and human primary normal colorectal fibroblasts were transiently transfected with siRNA using the Lipofectamine 3000 Transfection Reagent (Invitrogen, L3000-015) based on the manufacturer's instructions.

\section{Construction of stable cell lines}

The lentivirus vector LV17 (EF-1a/Luciferase17\&Puro) carrying the human CCL5-overexpressing sequence (CCL5) and the lentivirus vector LV16 (U6/ 
Firefly\&Puro) carrying the indicated CCL5-repressing short hairpin RNA (shRNA) sequence (GGGTTCGGG AGTACATCAA) (shCCL5) were obtained from GenePharma (Suzhou, China). Empty LV17 and LV16 vectors served as controls for the overexpression $(\mathrm{Vec})$ and repression vectors $(s h C t r l)$, respectively. Based on the manufacturer's instructions, stable cell lines were established by transfecting human CRC cell lines with these lentiviral vectors.

\section{Orthotopic CRC xenograft mouse model}

BALB/C-nude mice (male, 3-5 weeks old) were purchased from GemPharmatech Co., Ltd (Guangdong, China). They were housed under specific pathogen-free conditions in the animal facility at the Shenzhen Hospital, Southern Medical University, China. All animal experiments were approved by the ethics committee of Shenzhen Hospital, Southern Medical University, China. First, $5 \times 10^{6}$ HCT116, SW620/shCtrl, or SW620/shCCL5 cells were subcutaneously injected into the backs of nude mice $(n=3)$. After 2 weeks, the IVIS Spectrum In Vivo Imaging System (PerkinElmer, USA) was used to image tumor progression in mice with SW620/shCtrl and SW620/shCCL5 xenografts. Further, $15 \mathrm{mg} / \mathrm{ml} \mathrm{D-Lucif-}$ erin potassium salts (Promega, P1043) were intraperitoneally administered to the mice (dose, $10 \mu \mathrm{l} / \mathrm{g}$ ). The mice were sacrificed, and tumors were surgically removed, fixed in $10 \%$ formalin, embedded in paraffin, and cut into $2.5-\mu \mathrm{m}$-thick sections for hematoxylin-eosin (H\&E) staining.

After the subcutaneous tumors of HCT116 formed, one part of tumor tissues was fixed and stained with $H \& E$, and the remaining tumor tissues were removed and cut into $1-\mathrm{mm}^{3}$ pieces using ophthalmic scissors. Of these pieces, five were chosen and buried inside the cecal serosal layer in nude mice using purse string sutures $(n=5)$. After 8 weeks, the ceca of nude mice were surgically removed and processed as mentioned above.

\section{Immunoblot/western blot (WB)}

Total proteins were isolated from cells using the RIPA lysis buffer (FDbio, FD008), PMSF (FDbio, FD0100), Protease inhibitors (FDbio, FD1001), and protein phosphatase inhibitors (FDbio, FD1002). The concentration was determined using BCA protein assay kits (FDbio, FD2001). The total proteins were separated using $10 \%$ sodium dodecyl sulfate-polyacrylamide gel electrophoresis (SDS-PAGE) and transferred to polyvinylidene fluoride (PVDF) membranes. The membranes were blocked with 5\% skim milk (FDbio, FD0080) or 5\% BSA (FDbio, FD0030) for $1 \mathrm{~h}$ at $25{ }^{\circ} \mathrm{C}$ and then incubated with primary antibodies at $4{ }^{\circ} \mathrm{C}$ overnight.
Subsequently, the membranes were incubated with a goat anti-rabbit or anti-mouse secondary antibody (FDbio, FDR007 and FDM007). The proteins were detected using an ECL chemiluminescence solution (FDbio, FD8030) and visualized using a chemiluminescence detection system (Universal Hood II, Bio-Rad). The intensity of each immunoblot band was quantified using the NIH Image J software (National Institutes of Health, USA).

\section{Treatment with CCR1, CCR5, and Akt inhibitors}

Before the recruitment assay, fibroblasts were precultured with a CCR1 inhibitor (BX471, $100 \mathrm{nM}$, MedChemExpress, HY-12080A), CCR5 inhibitor (Maraviroc, $100 \mathrm{nM}$, Selleck, S2003), or Akt inhibitor (MK-2206, $2 \mu \mathrm{M}$, Selleck, S1078) for $48 \mathrm{~h}$. During the recruitment assay, BX471, Maraviroc, or MK-2206 was added to both the upper and lower chambers.

\section{Transcriptome sequencing}

Total mRNA was extracted from fibroblasts before and after treatment with $40 \mathrm{ng} / \mathrm{ml}$ CCL5 for $24 \mathrm{~h}$. Sequencing libraries were generated using the NEBNext ${ }^{\circledR}$ UltraTM RNA Library Prep Kit for Illumina ${ }^{\circledR}$ (NEB, USA) following the manufacturer's recommendations, and index codes were added to attribute the sequences to each sample. The clustering of the index-coded samples was performed on a cBot Cluster Generation System using the TruSeq PE Cluster Kit v3-cBot-HS (Illumina) according to the manufacturer's instructions.

\section{Matrigel angiogenesis experiment}

First, the high-concentration Matrigel (BD, 354,248) was diluted to half the original concentration. Then, $10 \mu \mathrm{l}$ of this diluted Matrigel was added to each well of a $\mu$-Slide Angiogenesis Glass Bottom (Ibidi, 81,506) and allowed to polymerize for $30 \mathrm{~min}$ at $37^{\circ} \mathrm{C}$. Subsequently, $50 \mu \mathrm{l}$ medium containing $1 \times 10^{4}$ fibroblasts (treated or not treated with $40 \mathrm{ng} / \mathrm{ml} \mathrm{CCL5}$ for $24 \mathrm{~h}$ ) was incubated in the diluted high-concentration Matrigel. After $2 \mathrm{~h}$, the fibroblasts were fixed with $4 \%$ paraformaldehyde and stained with hematoxylin. The number of lumens was obtained across three random visual fields using a light microscope, and capillary tubes were quantified by counting the number of lumens.

\section{Flow cytometry (Flow-Cyt)}

A $4{ }^{\circ} \mathrm{C}$ centrifuge was pre-cooled, and PBS containing $0.1 \%$ BSA was prepared in advance. Fibroblasts treated with $40 \mathrm{ng} / \mathrm{ml} \mathrm{CCL5}$ for $24 \mathrm{~h}$ and untreated fibroblasts were collected and washed with PBS. These cells 
were incubated with the APC-VE-cadherin antibody or APC-rabbit-IgG antibody at $4{ }^{\circ} \mathrm{C}$ for 30 min under dark conditions. Then, the cells were washed again with PBS. Finally, the cells were resuspended in $100 \mu \mathrm{l}$ of PBS, and the cell suspension was transferred to a flow cytometry tube for detection. The fluorescence intensity of fluorescein isothiocyanate was quantified using the Flow-jo software (BD, USA).

\section{Sirius red staining}

Sirius Red staining was performed on paraffin-embedded sections of human CRC tissue and tumor tissue from mouse caecum using the Sirius Red Staining Kit (LEAGENE, DC0041) based on the manufacturer's protocol. The degree of staining was observed under a polarized light microscope (Olympus, Japan) and scored independently by three pathologists. The percent positivity of Sirius Red staining was scored from 0 to 4 , as follows: $0(<5 \%), 1$ (5-25\%), $2(26-50 \%), 3$ $(51-75 \%)$, and $4(>75 \%)$. The staining intensity was scored on a 4-point scale, as follows: 0 (no staining), 1 (weak staining, light orange and/or green), 2 (moderate staining, medium orange and/or green), and 3 (strong staining, orange and/or green). Subsequently, the Sirius Red staining score was calculated by multiplying the percent positivity score with the staining intensity score. Accordingly, the level of Sirius Red staining was categorized as low (0-4), medium (5-8), or high (9-12).

\section{Bioinformatics analysis of relapse-free survival and correlation with mRNA expression in CRC patients}

The human CRC microarray profile GSE39582 was used to analyze the correlation of COL1 and COL3 expression with relapse-free survival in CRC patients. The chip platform used in this analysis was the Affymetrix Human Genome U133 Plus 2.0 Array. Based on the median values of COL1 and COL3 mRNA expression, patients were divided into low and high expression groups. Each group contained mRNA values for 283 patients. Then, the survival curves of the two groups were obtained using the Kaplan-Meier method. In addition, the human CRC microarray profile GSE39582 was also used to analyze the correlation of CCL5 expression with COL1 and COL3 expression.

\section{Scanning electron microscopy}

Fresh subcutaneous tumor tissues from nude mice $\left(\leq 3 \mathrm{~mm}^{3}\right)$ were surgically removed immediately after the mice were sacrificed. The tissues were promptly added to a fixative solution for electron microscopy (Servicebio, G1102) and incubated for $2 \mathrm{~h}$ at room temperature before being transferred to $4{ }^{\circ} \mathrm{C}$ for storage. Subsequently, the samples were observed and photographed using a scanning electron microscope (Hitachi, Japan).

\section{Statistical analysis}

SPSS software for Mac OS version 25.0 (IBM, USA) was used for statistical analyses. An unpaired two-tailed Student's $t$ test was used to analyze the differences between two groups. The Mann-Whitney U test was conducted to compare the scores of CCL5 staining or Sirius Red staining between CRC tumor tissues and adjacent normal tissues. Pearson's $\chi^{2}$ test and Spearman's correlation test were applied to analyze the correlation of CCL5 expression or the level of Sirius Red staining with clinicopathological features. The log-rank test was performed to analyze Kaplan-Meier survival curves. The correlation of CCL5 expression with the level of Sirius Red staining in CRC tissues, and the correlation of CCL5 mRNA expression with COL1 or COL3 mRNA expression in the human CRC microarray profile GSE39582 were analyzed using Spearman's correlation test. All data were expressed as the mean \pm standard deviation (SD). $P<0.05$ was considered statistically significant (ns, no significance; *, $P<0.05$; **, $P<0.01$; ***, $P<0.001)$.

\footnotetext{
(See figure on next page.)

Fig. 1 CRC tumor cells can recruit fibroblasts to tumor buds. a Representative H\&E images of human CRC tissue at the invasive front without (the upper panel) or with (the lower panel) tumor budding. The red triangles indicate the tumor buds. Data, $n=195$. Scale bar, $50 \mu \mathrm{m}$. b Representative a-SMA, CD90, and FAP IHC staining images of human CRC tissue at the invasive front without (the upper panel) or with (the lower panel) tumor budding. The red triangles indicate the tumor buds. Data, $n=17$. Scale bar, $50 \mu \mathrm{m}$. c Representative E-cad, VIM, and a-SMA IF images of human normal colorectal fibroblast cell line (CCD-18Co) and human primary normal colorectal fibroblast (NF1). Human CRC tumor cell line SW620 is the positive control for E-cad and the negative control for VIM and a-SMA. Scale bar, $20 \mu \mathrm{m}$. d Model diagram of recruitment assay of CRC tumor cells to fibroblasts. e Recruitment assay showing the recruitment ability of medium (Med), human normal colorectal epithelial cell line (FHC) and eight human CRC tumor cell lines (LS174T, RKO, DLD-1, Caco2, SW620, HCT-8, HCT116, HCT-15) to CCD-18Co or human primary normal colorectal fibroblast (NF1). Scale bar, $100 \mu \mathrm{m}$. Quantification of cell numbers of recruited fibroblasts is shown in the upper panel. Data, mean \pm SD; $n=5$. $\mathbf{f}$ Representative morphology images of tumor formation in the mouse caecum (the upper line), and H\&E images of normal mouse caecum and tumor tissue in the mouse caecum (the lower two lines). The red arrows indicate the tumors in the mouse caecum. Data, normal, $n=5 ;$ tumor, $n=5$. Scale bar, $50 \mu \mathrm{m}$. E-cad, E-cadherin; VIM, vimentin. ns, no significance; ${ }^{*}, P<0.05 ;{ }^{* *}, P<0.01 ;{ }^{* * *}, P<0.001$ by two-tailed Student's $t$ test (e)
} 


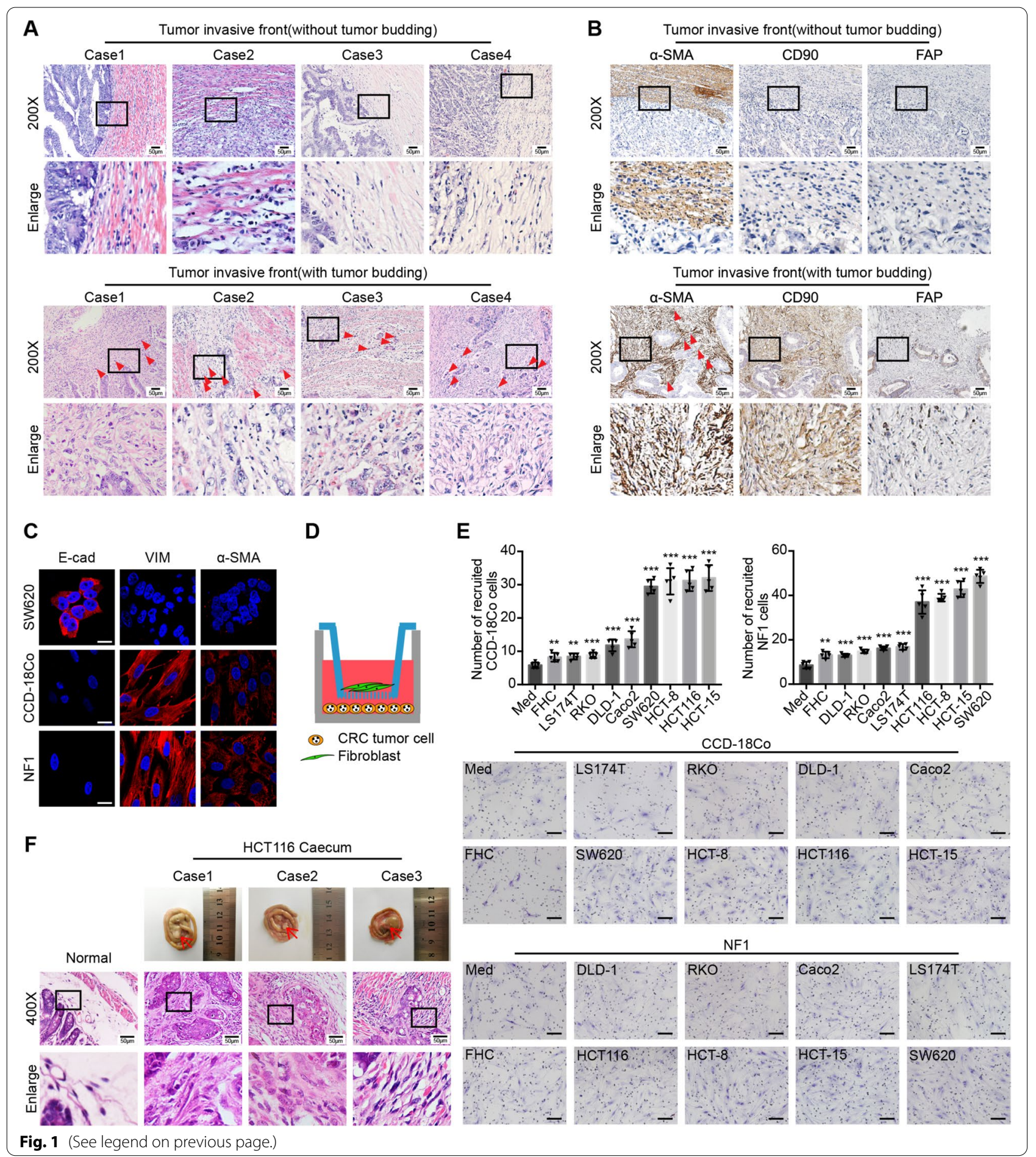

\section{Results}

\section{CRC tumor cells can recruit fibroblasts to tumor buds}

The evaluation of 195 clinical CRC tissue samples using $\mathrm{H} \& \mathrm{E}$ staining showed that the tumor budding-containing invasive front of CRC tissues had more fibroblasts than other parts of the tumor without tumor budding (Fig. 1a).
Next, we verified that the fibroblasts around tumor buds showed a high expression of $\alpha$-SMA and CD90 but a low expression of FAP $\left(\alpha-\right.$ SMA $^{\text {high }}$ CD $90^{\text {high }}$ FAP $^{\text {low }}$ (Fig. 1b). These results indicated that tumor budding at the invasive front of CRC tissues was closely related to fibroblast heterogeneity. 
Recently, several studies have demonstrated that fibroblasts can be recruited through the effects of cytokines secreted from tumor cells or other cells in the TME [7, 27-29]. While exploring the contribution of CRC cells to fibroblast recruitment, two types of fibroblasts were used: the human normal colorectal fibroblast cell line CCD-18Co and human primary normal colorectal fibroblast, NF1. The human primary normal colorectal fibroblasts were isolated through the enzyme digestion or improved tissue planting method (Additional file 1: Figure S1A). To identify these fibroblasts, the epithelial marker E-cadherin and fibroblast markers vimentin and $\alpha$-SMA were detected using IF (Fig. 1c and Additional file 1: Figure S1B).

Next, a co-culture recruitment assay was conducted (Fig. 1d). In this assay, human CRC tumor cells were incubated in the lower chamber, while fibroblasts were incubated in the upper chamber. The pore size of the upper co-culture chamber was $8 \mu \mathrm{m}$ - big enough to allow fibroblasts to pass through. As shown in Fig. 1e, FHC (human normal colorectal epithelial cell line) and LS174T, RKO, DLD-1, and Caco2 (human CRC cell lines) showed a weak ability to recruit fibroblasts. In contrast, HCT-8, HCT116, HCT-15, and SW620 (human CRC cell lines) showed a stronger recruitment ability.

Subsequently, HCT116 cells, which showed a strong ability to recruit fibroblasts in vitro, were used for further in vivo orthotopic CRC xenograft mouse experiments. Using H\&E staining to examine tumors in the mouse cecum, we observed that HCT116 could also recruit fibroblasts in vivo (Fig. 1f). Taken together, these data demonstrated that tumor buds of CRC tumors can recruit fibroblasts.

\section{CRC tumor cells in tumor buds recruit fibroblasts via CCL5}

To further ascertain which key cytokine secreted by CRC tumor cells is responsible for fibroblast recruitment, the CM samples from FHC, which had a weak ability to recruit fibroblasts, and the CM samples from HCT-8, HCT116, HCT-15, and SW620 (human CRC cell lines), which possessed a stronger recruitment ability, were analyzed using a human cytokine array (Fig. 2a). GO functional enrichment analysis indicated that the proteins differentially expressed between these groups were involved in various activities, including "positive regulation of cell migration" (Fig. 2b) and "extracellular matrix" (Additional file 2: Figure S2A). This suggested that cytokines secreted by CRC tumor cells could recruit other cells in the TME and could be involved in the recruitment of fibroblasts, which are the main source of extracellular matrix [1].

Among the differentially expressed proteins, CCL5 showed the most up-regulation in CM samples from human CRC tumor cells (Fig. 2c). The mRNA and secreted protein levels of CCL5 were examined in FHC and eight human CRC tumor cell lines, and the results were entirely consistent with initial findings from the co-culture recruitment assay (Fig. 2d, e). Furthermore, CCD-18Co and human primary normal colorectal fibroblasts were found to secrete lower levels of CCL5 than FHC (Fig. 2f). Accordingly, it appeared that the CCL5-mediated recruitment of fibroblasts occurred through paracrine and not autocrine signaling. Next, the expression of CCL5 was detected in human CRC tissues using IHC, and the results showed that CCL5 was highly expressed in tumor buds at the invasive front (Fig. 2g).

Then, to examine whether CCL5 is the key cytokine for fibroblast recruitment, another recruitment assay was performed (Fig. 2h). Among the different concentrations

\footnotetext{
(See figure on next page.)

Fig. 2 CRC tumor cells in tumor buds recruit fibroblasts via CCL5. a Heatmap of the differentially expressed proteins in the cytokine array of the CM samples from FHC (owning a weak recruitment ability) and four human CRC tumor cell lines (HCT-8, HCT116, HCT-15, SW620, owning a strong recruitment ability). The cytokine array detected 1000 cytokines. b The differentially expressed proteins in the cytokine were analyzed by GO biological process functional enrichment analysis. c Part of the cytokine array including CCL5 showing the expression of CCL5 in the CM samples from FHC and HCT116, HCT-8, HCT-15, SW620. d Relative expression of CCL5 mRNA in FHC and eight human CRC tumor cell lines. Data, mean \pm SD; $n=3$. e Supernatant CCL5 levels in the CM samples from FHC and eight human CRC tumor cell lines. Data, mean \pm SD; $n=3$. f Supernatant CCL5 levels in the CM samples from FHC, CCD-18Co and human primary normal colorectal fibroblasts (NF4, NF5, NF6, NF7). Data, mean \pm SD; $n=3$. $\mathbf{g}$ Representative CCL $5 \mathrm{IHC}$ staining images of human CRC tissue at the invasive front without (the left column) or with (the right four columns) tumor budding. The red triangles indicate the tumor buds. Scale bar, $50 \mu \mathrm{m}$. h Model diagram of recruitment assay of CCL5 to fibroblasts. $\mathbf{i}$ Quantification of cell numbers of CCD-18Co and human primary normal colorectal fibroblasts (NF1, NF4, NF5, NF6, NF7, NF8, NF9) recruited by 40 ng/ml CCL5. Data, mean $\pm S D ; n=5$. $\mathbf{j}$ Model diagram of recruitment assay of CCL5 knockdown and overexpressing human CRC tumor cell lines to fibroblasts. k Quantification of cell numbers of CCD-18Co recruited by HCT-8/siCtrl and HCT-8/siCCL5, SW620/siCtrl and SW620/siCCL5. Data, mean \pm SD; $n=5$. I Quantification of cell numbers of CCD-18Co recruited by RKO/Vec and RKO/CCL5, LS174T/Vec and LS174T/CCL5. Data, mean \pm SD; $n=5$. $\mathbf{m}$ Model diagram of recruitment assay of the CM samples from CCL5 knockdown and overexpressing human CRC tumor cell lines to fibroblasts. $\mathbf{n}$ Quantification of cell numbers of CCD-18Co recruited by the CM samples from HCT-8/shCtrl and HCT-8/shCCL5, SW620/shCtrl and SW620/shCCL5. Data, mean $\pm S D ; n=5$. o Quantification of cell numbers of CCD-18Co recruited by the CM samples from RKO/Vec and RKO/CCL5, LS174T/Vec and LS174T/CCL5. Data, mean \pm SD; $n=5$. ns, no significance; *, $P<0.05 ;{ }^{* *}, P<0.01 ; * * *, P<0.001$ by two-tailed Student's $t$ test $(\mathbf{d}, \mathbf{e}, \mathbf{f}, \mathbf{i}, \mathbf{k}, \mathbf{l}, \mathbf{n}, \mathbf{o})$
} 


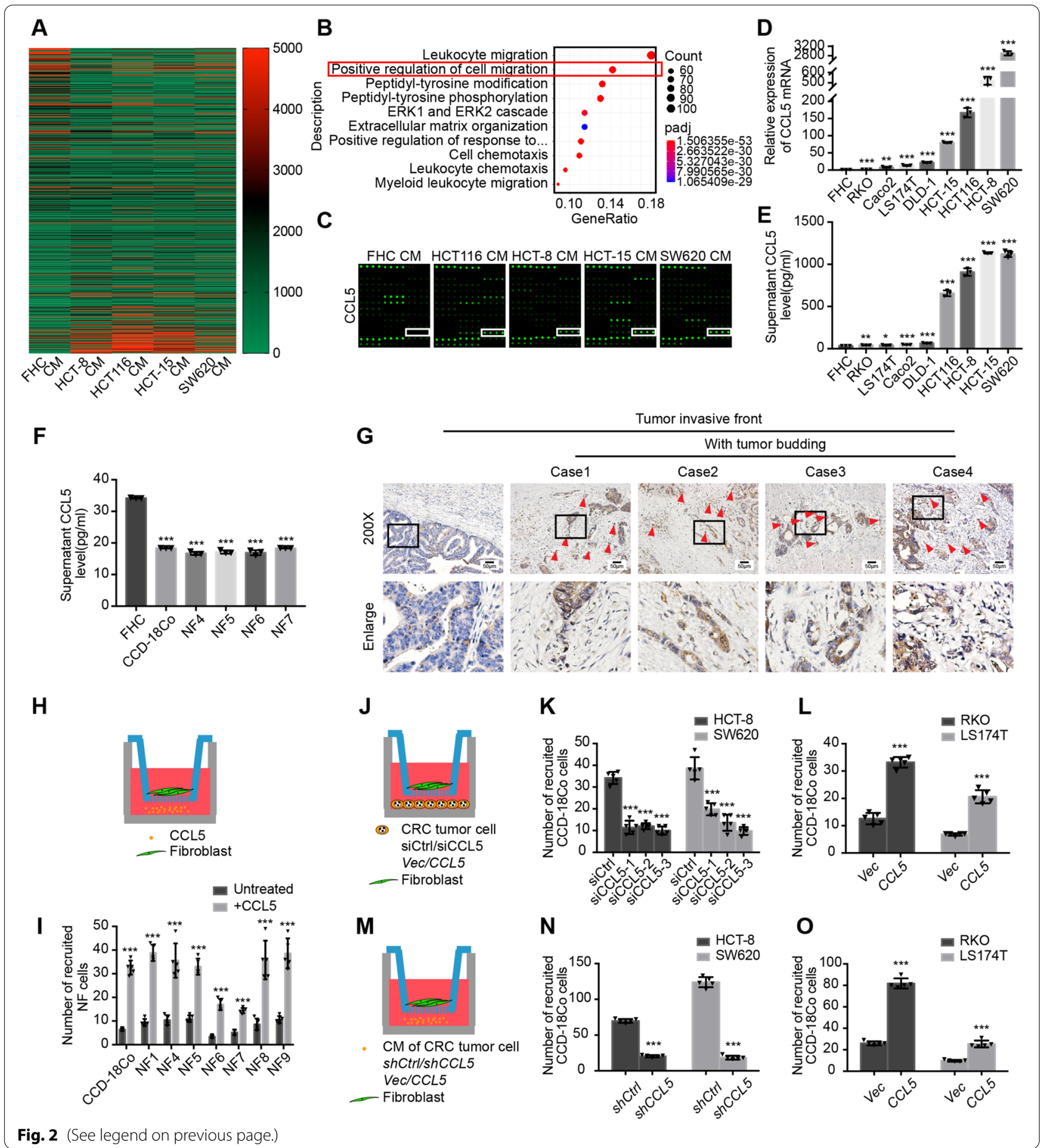

of CCL5, $40 \mathrm{ng} / \mathrm{ml} \mathrm{CCL5}$ showed the strongest ability to recruit fibroblasts (Additional file 2: Figure S2B). At this concentration, CCL5 could recruit CCD-18Co and different human primary normal colorectal fibroblasts (Fig. 2i and Additional file 2: Figure S2C).
Finally, to ascertain whether the CCL5 that recruits fibroblasts was secreted by CRC tumor cells, CCL5 knockdown and overexpressing cell lines were established using siRNA and lentiviral constructs, respectively. The CCL5 mRNA and protein secretion levels in these cell lines were verified (Additional file 2: Figure 


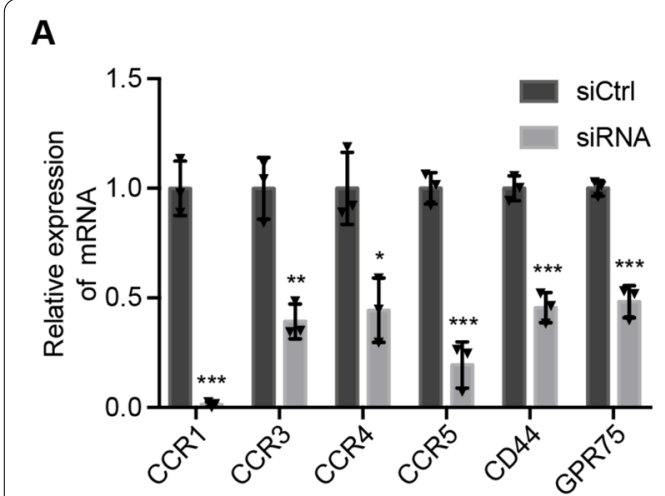

B

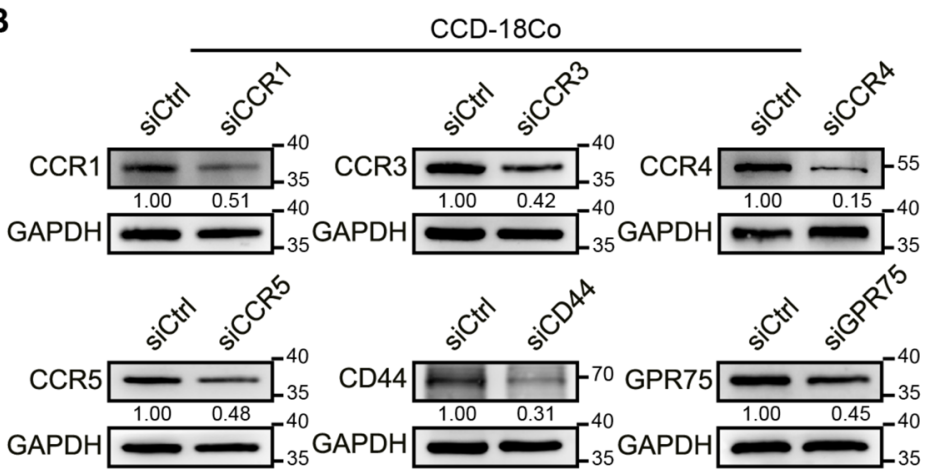

C

D
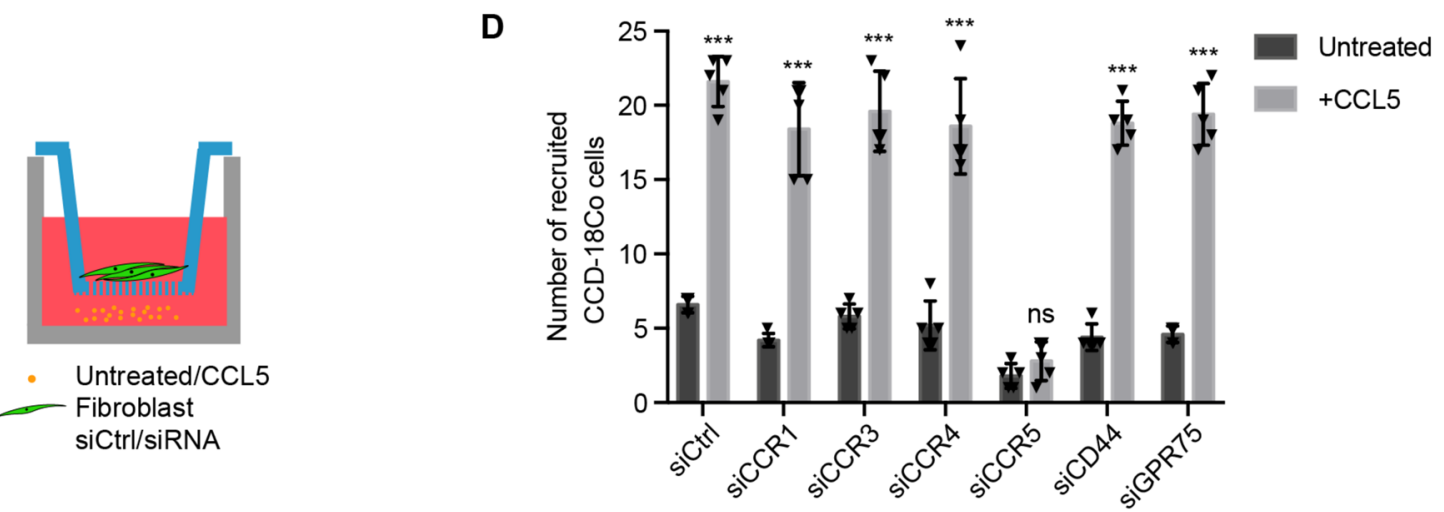

CCD-18Co

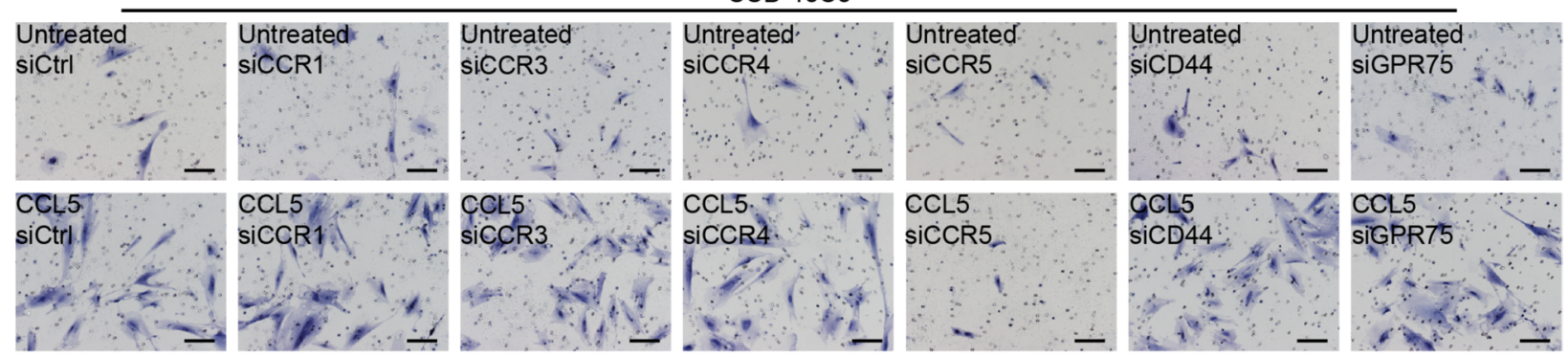

E

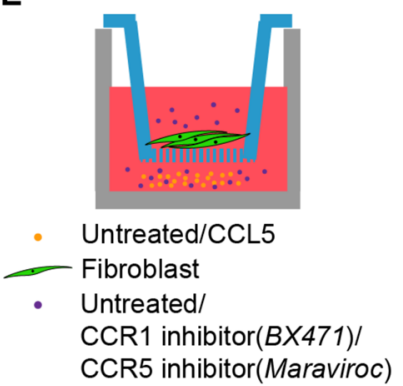

$\mathbf{F}$

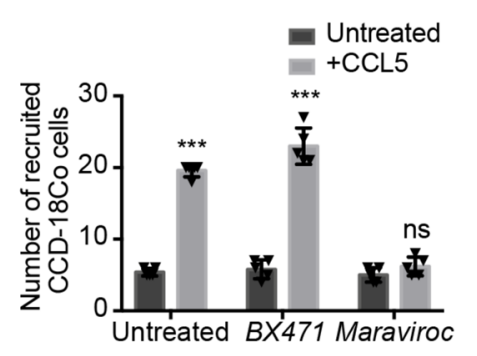

CCD-18Co

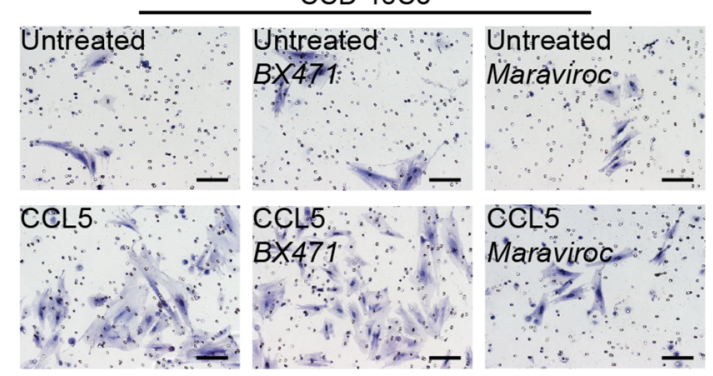

Fig. 3 CCL5 recruits fibroblasts through the CCR5 receptor. a Relative expression of CCR1, CCR3, CCR4, CCR5, CD44, GPR75 mRNA in CCD-18Co/ siCtrl and CCD-18Co/siRNA. Data, mean \pm SD; $n=3 . \mathbf{b}$ Immunoblots for CCR1, CCR3, CCR4, CCR5, CD44, GPR75 protein expression in CCD-18Co/ siCtrl and CCD-18Co/siRNA. c Model diagram of recruitment assay of $40 \mathrm{ng} / \mathrm{ml} \mathrm{CCL5}$ to CCR1, CCR3, CCR4, CCR5, CD44, or GPR75 knockdown fibroblasts. d Recruitment assay showing the recruitment ability of $40 \mathrm{ng} / \mathrm{ml} \mathrm{CCL} 5$ to CCD-18Co/siCtrl and CCD-18Co/siRNA. Scale bar, $100 \mu \mathrm{m}$. Quantification of cell numbers of recruited CCD-18Co cells is shown in the upper panel. Data, mean \pm SD; $n=5$. e Model diagram of recruitment assay of $40 \mathrm{ng} / \mathrm{ml} \mathrm{CCL5}$ to fibroblasts without or with CCR1 inhibitor (BX471) or CCR5 inhibitor (Maraviroc). f Recruitment assay showing the recruitment ability of $40 \mathrm{ng} / \mathrm{ml}$ CCL5 to CCD-18Co without or with BX471 or Maraviroc. Scale bar, $100 \mu \mathrm{m}$. Quantification of cell numbers of recruited CCD-18Co cells is shown in the left panel. Data, mean \pm SD; $n=5$. ns, no significance; ${ }^{*}, P<0.05 ;{ }^{* *}, P<0.01 ;{ }^{* * *}, P<0.001$ by two-tailed Student's $t$ test $(\mathbf{a}, \mathbf{d}, \mathbf{f})$ 
S2D-G). A co-culture recruitment assay (Fig. 2j) showed that the ability of tumor cells to recruit fibroblasts was significantly weakened after CCL5 knockdown (Fig. 2k and Additional file 2: Figure S2H). In contrast, this ability was enhanced when CCL5 was overexpressed (Fig. 21 and Additional file 2: Figure S2I). In the recruitment assay, the CM samples from stable cells (Fig. $2 \mathrm{M}$ and Additional file 2: Figure S2J, K) showed effects similar to those observed with whole cells (Fig. $2 \mathrm{~N}, \mathrm{O}$ and Additional file 2: Figure S2L, M). Together, these results revealed that CCL5 was highly expressed in CRC tumor buds and could recruit fibroblasts from the TME.

\section{CCL5 recruits fibroblasts through the CCR5 receptor}

CCR1, CCR3, CCR4, CCR5, CD44, and GPR75 are known to be possible receptors of CCL5 $[18,19]$. Accordingly, to explore whether CCL5 mediates fibroblast recruitment through these receptors, siRNA was used to knock down their expression respectively in fibroblasts, and the interference efficiency was verified (Fig. 3a, b). Next, recruitment assays were performed, as described in Fig. 3c. Surprisingly, only CCR5 downregulation in fibroblasts could significantly attenuate the ability of CCL5 to recruit fibroblasts (Fig. 3d).

Further, the CCR1 inhibitor $B X 471$ and CCR5 inhibitor Maraviroc were used to treat fibroblasts and blocking CCR1 and CCR5, respectively, before and during the co-culture recruitment assay (Fig. 3e). Only Maraviroc treatment significantly weakened the ability of CCL5 to recruit fibroblasts (Fig. 3f). The above results strongly indicated that CCL5 was involved in fibroblast recruitment through the CCR5 receptor.

\section{CCL5-dependent fibroblast recruitment is mediated by SLC25A24 in fibroblasts}

In order to explore the intracellular changes in fibroblasts after CCL5 stimulation, fibroblasts were examined using transcriptome sequencing before and after CCL5 treatment (Fig. 4a). The top 20 differentially expressed genes were selected and verified in CCD-18Co and human primary normal colorectal fibroblasts before and after CCL5 treatment. Among the selected genes, SLC25A24 was found to be consistently up-regulated (Additional file 3: Figure S3A). We subsequently verified that the levels of SLC25A24 mRNA were up-regulated in more types of human primary normal colorectal fibroblasts after CCL 5 treatment (Fig. 4b).

SLC25A24, also known as ATP- $\mathrm{Mg}^{2+} /$ phosphate carrier 1 (APC1), has a regulatory $\mathrm{N}$-terminal domain containing EF-hand $\mathrm{Ca}^{2+}$ binding sites, which allow transport in response to cytosolic $\mathrm{Ca}^{2+}$ elevations [3032]. To detect the protein expression and localization of SLC25A24 in human CRC tissues, IF assays were performed. The results revealed that SLC25A24 was highly expressed in the fibroblasts surrounding the tumor buds at the invasive front (Fig. 4c). In vivo, in tumor xenografts of shCCL5-transfected CRC cells, reduced SLC25A24 expression was observed in fibroblasts (Fig. 4d). Furthermore, tumor progression was also inhibited (Additional file 3: Figure S3B). Next, we further verified that CCL5 could up-regulate the expression of SLC25A24 protein in vitro (Additional file 3: Figure S3C).

Functionally, to explore whether CCL5-mediated fibroblast recruitment was dependent on SLC25A24, siRNA against SLC25A24 was transfected into fibroblasts, and the recruitment assay was performed (Fig. 4e). A reduction of SLC25A24 expression in fibroblasts significantly attenuated the ability of CCL5 to recruit fibroblasts (Fig. 4f, g and Additional file 3: Figure S3D). Moreover, immunoblot results demonstrated that elevations of SLC25A24 expression in fibroblasts after CCL5 stimulation were dependent on CCR5 (Additional file 3: Figure S3E). This demonstrated CCL5-mediated fibroblast recruitment was dependent on SLC25A24 and CCR5.

\footnotetext{
(See figure on next page.)

Fig. 4 CCL5-dependent fibroblast recruitment is mediated by SLC25A24 in fibroblasts. a Heatmap of the differentially expressed genes in the transcriptome sequencing of CCD-18Co before and after $40 \mathrm{ng} / \mathrm{ml} \mathrm{CCL5}$ stimulation for $24 \mathrm{~h}$. Data, $n=3$. b Relative expression of SLC25A24 mRNA in CCD-18Co and human primary normal colorectal fibroblasts (NF1, NF2, NF3, NF4, NF5, NF6, NF7, NF8, NF9) before and after 40 ng/ml CCL5 stimulation for $24 \mathrm{~h}$. Data, mean $\pm S D ; n=3$. c Representative $a-S M A$ and SLC25A24 IF images at the invasive front of human CRC tissue without (the upper panel) or with (the lower panel) tumor budding trend. Data, $n=10$. Scale bar, $100 \mu \mathrm{m}$. d Representative SLC25A24 IHC staining images of mouse subcutaneous tumors with the injection of SW620/shCtrl or SW620/shCCL5. Data, $n=3$. Scale bar, $50 \mu$ m. e Model diagram of recruitment assay of $40 \mathrm{ng} / \mathrm{ml}$ CCL5 to SLC25A24 knockdown fibroblasts. $\mathbf{f} /$ mmunoblots for SLC25A24 protein expression of CCD-18Co/siCtrl and CCD-18Co/siSLC25A24, NF4/siCtrl and NF4/siSLC25A24, NF7/siCtrl and NF7/siSLC25A24. g Quantification of cell numbers of CCD-18Co/siCtrl and CCD-18Co/siSLC25A24, NF4/siCtrl and NF4/siSLC25A24, NF7/siCtrl and NF7/siSLC25A24 recruited by $40 \mathrm{ng} / \mathrm{ml}$ CCL5. Data, mean \pm SD; $n=5$. $\mathbf{h}$ The differentially expressed genes in the transcriptome sequencing were analyzed by KEGG enrichment analysis. $\mathbf{i}$ Immunoblots for SLC25A24, PI3K, p-PI3K, Akt, p-Akt, mTOR, p-mTOR protein expression in CCD-18Co before and after different concentration of CCL5 stimulation for $24 \mathrm{~h}$ (the left panel) and those proteins in CCD-18Co/siCtrl and CCD-18Co/siSLC25A24 after $40 \mathrm{ng} / \mathrm{ml} \mathrm{CCL5} \mathrm{stimulation} \mathrm{for} 24 \mathrm{~h}$ (the right panel). SLC, SLC25A24; P-PI3K, phosphorylated PI3K; p-Akt, phosphorylated Akt; P-mTOR, phosphorylated mTOR. ns, no significance; ${ }^{*}, P<0.05 ;{ }^{* *}, P<0.01$; ${ }^{* *}, P<0.001$ by two-tailed Student's $t$ test $(\mathbf{b}, \mathbf{g})$
} 


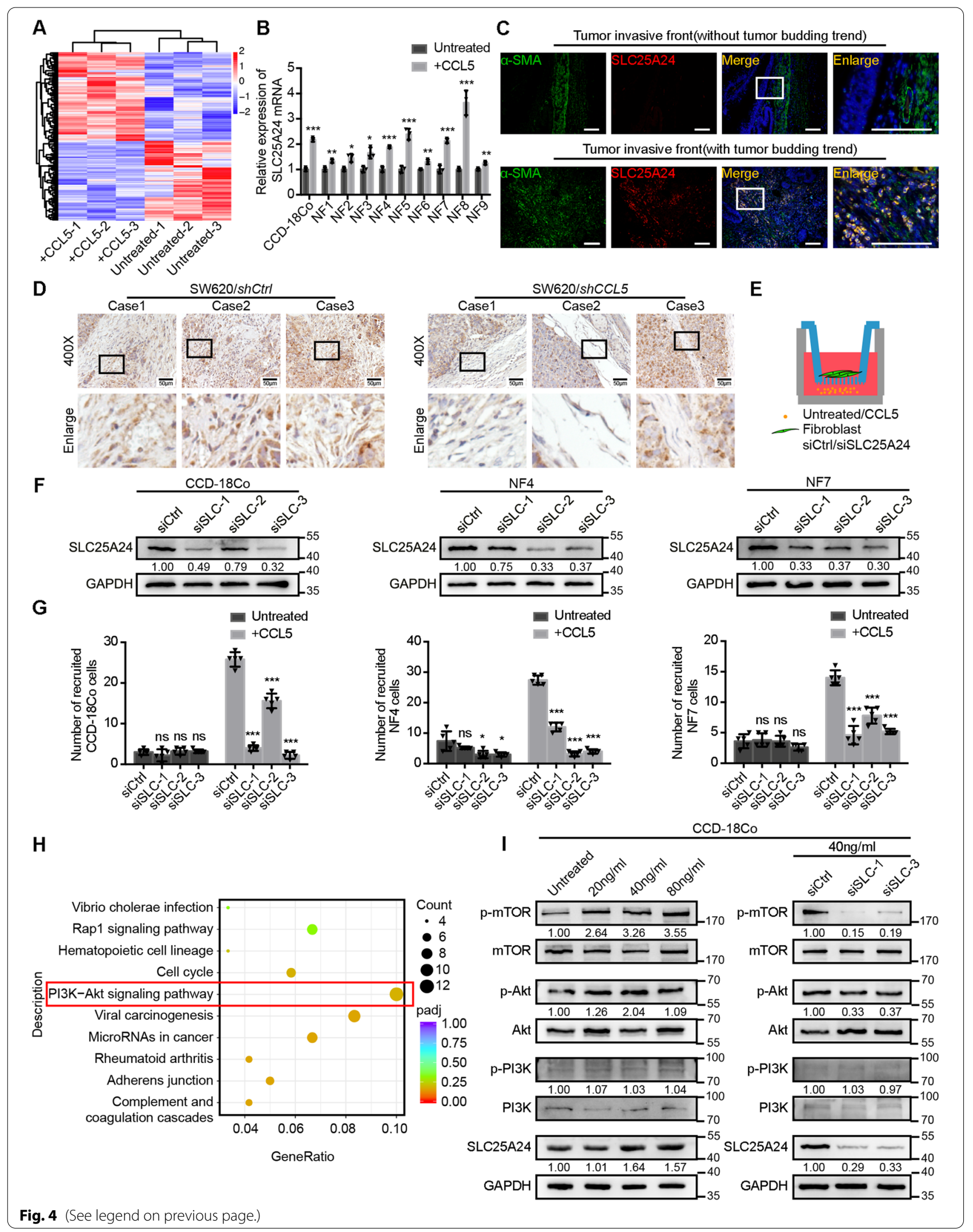


To further ascertain which pathways were activated by CCL5 and SLC25A24 in fibroblasts, KEGG enrichment analysis was performed using transcriptome sequencing data. The PI3K-Akt signaling pathway was shown to be the most active after CCL5 stimulation (Fig. 4h). Immunoblot results showed that CCL5 could promote the phosphorylation of Akt and mTOR in fibroblasts (Fig. 4i, left panel). In contrast, when SLC25A24 expression was inhibited, the levels of phosphorylated Akt and mTOR decreased in fibroblasts after CCL5 stimulation (Fig. 4i, right panel). Furthermore, inhibiting Akt phosphorylation in fibroblasts reduced the fibroblast recruitment ability of CCL5 (Additional file 3: Figure S3F). However, this inhibition had no effect on the expression of SLC25A24 (Additional file 3: Figure S3G). These findings suggested that CCL5 recruited fibroblasts through the SLC25A24pAkt-pmTOR axis within fibroblasts.

\section{CCL5 contributes to the increase in a-SMA ${ }^{\text {high }} C D 90^{\text {high }}$ FAP ${ }^{\text {low }}$ fibroblasts and thereby promotes tumor angiogenesis}

Our initial findings (Fig. 1b) proved that fibroblasts around tumor buds were $\alpha$-SMA ${ }^{\text {high }}, \mathrm{CD} 90^{\text {high }}$, and FAP $^{\text {low. }}$ To examine whether CCL5 is the main contributor to the increase in $\alpha$-SMA ${ }^{\text {high }} \mathrm{CD} 90^{\text {high }}$ FAP ${ }^{\text {low }}$ fibroblasts, an IF assay was performed. This assay showed that the expression of $\alpha$-SMA and CD90 was elevated in fibroblasts treated with CCL5 (Fig. 5a). VEGFA is necessary for the proliferation, survival, migration, and invasion of vascular endothelial cells into surrounding tissue and the subsequent generation of lumen-containing structures [33]. It has been reported that fibroblasts are one of the main sources of VEGFA [2]. Furthermore, studies have shown that fibroblasts can transdifferentiate into vascular endothelial cells and facilitate tumor progression [34-36]. We examined the role of CCL5 in fibroblastmediated angiogenesis. Immunoblots showed that the levels of the vascular endothelial markers FLI1, VE-cadherin, CD31, and VEGFA as well as those of
$\alpha$-SMA and CD90 were elevated in fibroblasts treated with CCL5 (Fig. 5b). Flow cytometry also demonstrated that the proportion of the VE-cadherin ${ }^{+}$ subset of fibroblasts increased after CCL5 stimulation (Fig. 5c and Additional file 4: Figure S4A). Functionally, the proangiogenic ability of fibroblasts was also found to be enhanced after CCL5 stimulation (Fig. 5d). Serial sections from 10 clinical CRC samples were stained for CCL5, $\alpha$-SMA, CD90, FAP, CD31, and VEGFA using IHC. At the invasive front, CCL5 was highly expressed in tumor buds, which were surrounded by a high number of $\alpha$-SMA ${ }^{\text {high }} \mathrm{CD} 90^{\text {high }}$ FAP ${ }^{\text {low }}$ fibroblasts and blood vessels (Fig. 5e). Immunoblots and Matrigel angiogenesis experiments showed that when fibroblasts were transfected with SLC25A24 siRNA, there was no attenuation of the CCL5-mediated increase in angiogenesis (Additional file 4: Figure S4B, C). Based on these findings, we speculated that tumor bud-derived CCL5 increased the number of $\alpha$-SMA ${ }^{\text {high }} C D 90^{\text {high }}$ FAP ${ }^{\text {low }}$ fibroblasts and promoted tumor angiogenesis via the increase in VEGFA and the transdifferentiation of fibroblasts into vascular endothelial cells.

\section{CCL5 promotes collagen synthesis via fibroblasts, contributing to tumor progression}

GO functional enrichment analysis performed using transcriptome sequencing data indicated that CCL5 was also involved in extracellular matrix-related functions (Fig. 6a). It is well-established that collagen type I (COL1) and collagen type III (COL3) are the primary components of the extracellular matrix and are mainly synthesized and secreted by fibroblasts [2]. To clarify the role of CCL5 in collagen synthesis, immunoblots were performed. The findings demonstrated that CCL5 could increase the protein expression of COL1 and COL3 in fibroblasts in vitro (Fig. 6b).

To further investigate the role of CCL5 in CRC, the expression of the CCL5 protein was examined in 195 paraffin-embedded human CRC tissue samples and 162 human adjacent normal colorectal tissue samples.

\section{(See figure on next page.)}

Fig. 5 CCL5 contributes to the increase in a-SMA high $C D 90^{\text {high }}$ FAPlow fibroblasts and thereby promotes tumor angiogenesis. a Representative a-SMA, FAP and CD90 IF images of CCD-18Co and human primary normal colorectal fibroblast (NF1) before and after $40 \mathrm{ng} / \mathrm{ml}$ CCL5 stimulation for $24 \mathrm{~h}$. Scale bar, 40 mm. b Immunoblots for a-SMA, CD90, FLI1, VE-cad, CD31 and VEGFA protein expression in CCD-18Co and human primary normal colorectal fibroblast (NF1) before and after $40 \mathrm{ng} / \mathrm{ml}$ CCL5 stimulation for $24 \mathrm{~h}$. c Flow cytometry showing the proportion of VE-cad ${ }^{+}$subset in CCD-18Co and human primary normal colorectal fibroblast (NF1) before and after $40 \mathrm{ng} / \mathrm{ml}$ CCL5 stimulation for $24 \mathrm{~h}$. Quantification is shown in the left panel. Data, mean \pm SD; $n=3$. d Matrigel angiogenesis experiments showing the angiogenesis ability of CCD-18Co and human primary normal colorectal fibroblasts (NF1, NF2, NF3) before and after $40 \mathrm{ng} / \mathrm{ml} \mathrm{CCL5}$ stimulation. Scale bar, $100 \mu \mathrm{m}$. Quantification of increasing folds of tube formation is shown in the upper panel. Data, mean $\pm S D ; n=3$. e Representative CCL5, a-SMA, CD90, FAP, CD31 and VEGFA IHC staining images of human CRC tissue at the invasive front without (the upper panel) or with (the lower panel) tumor budding. The red triangles indicate the tumor buds. Data, $n=10$. Scale bar, $50 \mu \mathrm{m}$. VE-cad, VE-cadherin. ns, no significance; ${ }^{*} P<0.05 ;{ }^{* *}, P<0.01 ;{ }^{* *}, P<0.001$ by two-tailed Student's $t$ test (c, d) 


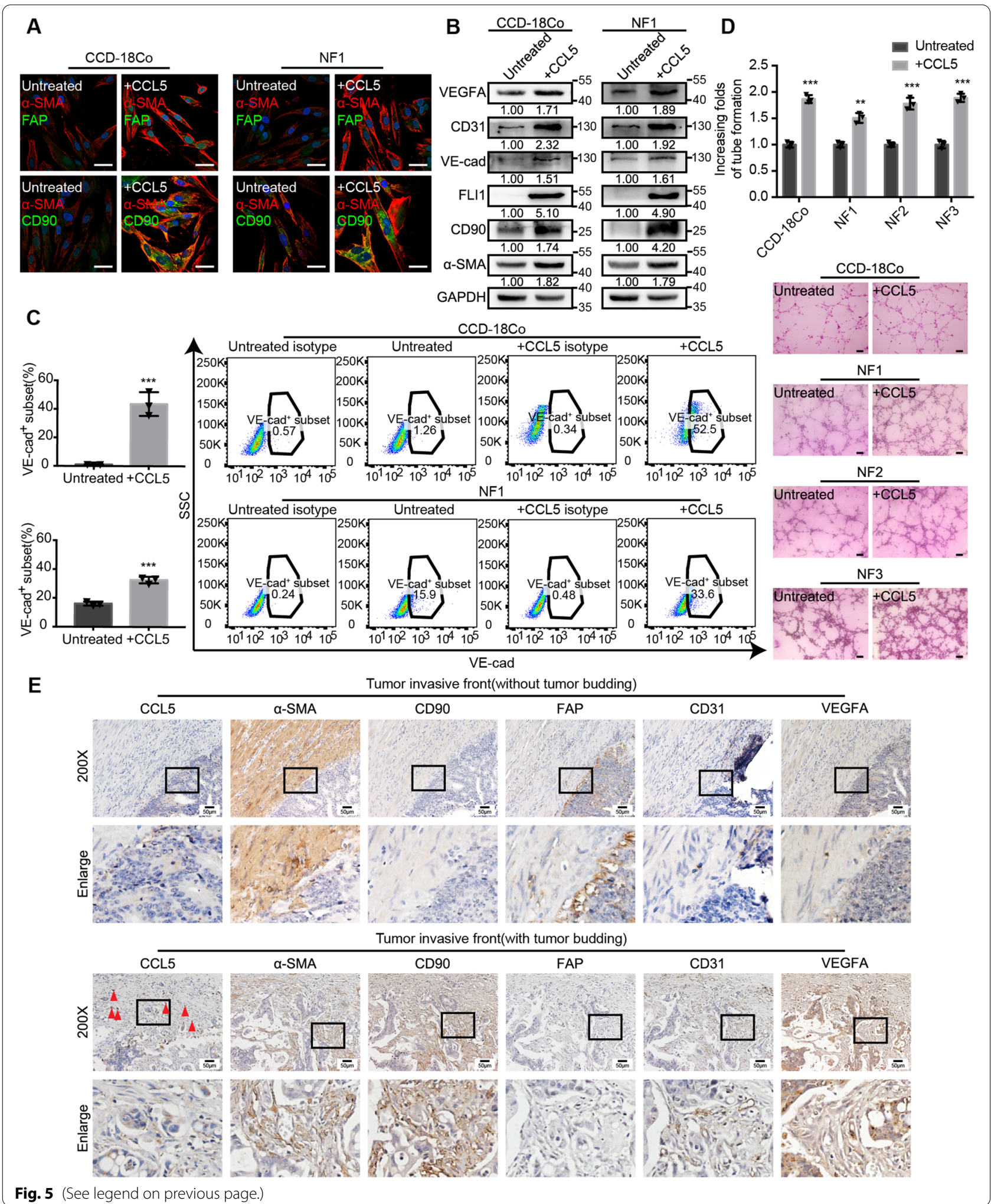


CCL5 expression was significantly higher in CRC tissues than in normal tissues (Fig. 6c and Additional file 5: Figure S5A). The correlation between CCL5 expression and clinical features was analyzed using Pearson's $X^{2}$ test (Table 1 ). Further Spearman's correlation tests showed that high levels of CCL5 expression were positively associated with a high risk of increased tumor buds $(r=0.583, P<0.001$, Fig. $6 \mathrm{~d})$, deep tumor invasion $(r=0.244, P=0.001)$, lymph node metastasis $(r=0.237, P=0.001)$, the presence of peri-intestinal cancer nodule deposition $(r=0.198$, $P=0.005)$, and advanced TNM stages $(r=0.256$, $P<0.001$ ) (Additional file 5: Figure S5B-E). Moreover, Sirius Red staining for COL1 (reddish) and COL3 (greenish) was performed to detect the collagen distribution in 88 of the 195 human CRC tissue samples. The expression of COL1 and COL3 was elevated in CRC tissue (Fig. 6e; Additional file 5: Figure S5F). The correlation between Sirius Red staining and the clinical features of CRC was also analyzed using Pearson's $X^{2}$ test (Table 2). Further Spearman's correlation tests showed that a high collagen distribution around CRC tumor cells was positively related to increased tumor buds ( $r=0.297, P=0.005$, Fig. $6 f$ ), deep tumor invasion $(r=0.431, P=0.001)$, lymph node metastasis ( $r=0.351, P=0.001)$, the presence of peri-intestinal cancer nodule deposition $(r=0.288, P=0.007)$, and advanced TNM stages $(r=0.442, P=0.001)$ (Additional file 5: Figure S5G-J). Intriguingly, the high expression of CCL5 in tumor buds at the invasive front was often accompanied by increased collagen synthesis (Fig. 6g). Spearman's correlation analyses revealed a positive correlation between the levels of CCL5 expression in tumor cells and the amounts of collagen in the surrounding area from the same CRC tissue sample $(n=88 ; r=0.317, P=0.003$, Fig. $6 \mathrm{~h})$.

Subsequently, HCT116 cells, which secrete large amounts of CCL5, were used to establish orthotopic
CRC xenograft mouse models for in vivo analysis. We found that collagen synthesis was increased around tumor cells at the invasive front (Fig. 6i). Furthermore, the human CRC microarray profile GSE39582 was used to analyze the relapse-free survival of patients with low and high expression of COL1 or COL3. A higher expression of COL1 and COL3 was closely related to a poor prognosis in CRC patients (Fig. 6j). Spearman's correlation analyses using GSE39582 also showed that CCL5 mRNA expression was correlated with COL1 mRNA $(r=0.211, P<0.001)$ and COL3 mRNA expression $(r=0.228, P<0.001)$ (Additional file 5: Figure S5K, $\mathrm{L})$. Moreover, immunoblots showed that the transfection of SLC25A24 siRNA in fibroblasts did not attenuate the CCL5-mediated increase in collagen synthesis (Additional file 5: Figure S5M). Additionally, collagen fibers in the tumor xenografts of shCtrl-transfected CRC cells were oriented in the same direction, forming thicker collagen fiber bundles. In contrast, the collagen fibers in the tumor xenografts of shCCL5transfected CRC cells were disorganized (Additional file 5: Figure S5N). These findings demonstrated that shCCL5 substantially attenuated collagen linearization in vivo, which was suggestive of attenuated stiffness and a subsequent reduction in tumor progression [37, 38]. Taken together, these results suggested that tumor buds secreted CCL5, which then promoted collagen synthesis via fibroblasts, thus contributing to tumor progression.

\section{Discussion}

The TME plays multiple roles in tumorigenesis because it harbors cancer cells that interact with surrounding cells and promote cancer progression [39, 40]. Inside the TME, fibroblasts exert strong tumor-modulating effects, which are closely related to disease recurrence and a poor prognosis [41-44]. Although fibroblasts play important roles in CRC development, specific markers

\footnotetext{
(See figure on next page.)

Fig. 6 CCL5 promotes collagen synthesis via fibroblasts, contributing to tumor progression. a The differentially expressed genes in the transcriptome sequencing were analyzed by GO functional enrichment analysis. $\mathbf{b}$ Immunoblots for COL 1 and COL3 protein expression in CCD-18Co and human primary normal colorectal fibroblast (NF4) before and after $40 \mathrm{ng} / \mathrm{ml} \mathrm{CCL5}$ stimulation for 24 h. c IHC scores of CCL5 in human adjacent normal tissues and CRC tumor tissues. Data, adjacent, $n=162$; tumor, $n=195$. (d) Spearman's correlation analysis of low and high expression of CCL5 in human CRC patients with the different tumor budding categories. Spearman $r=0.583$. Data, $n=195$. e Scores of Sirius Red staining in human adjacent normal tissues and CRC tumor tissues. Data, adjacent, $n=82$; tumor, $n=88$. $\mathbf{f}$ Spearman's correlation analysis of low and high level of Sirius Red staining in human CRC patients with the different tumor budding categories. Spearman $r=0.297$. Data, $n=88$. $\mathbf{g}$ Representative CCL5 IHC staining and Sirius Red staining images of human CRC tissue at the invasive front without (the left panel) or with (the right panel) tumor budding. The red triangles indicate the tumor buds. Scale bar, $50 \mu \mathrm{m}$. $\mathbf{h}$ Spearman's correlation analysis between the level of CCL5 expression and Sirius Red staining in human CRC tissues. Spearman $r=0.317$. Data, $n=88$. i Representative Sirius Red staining images of normal mouse caecum and tumor tissue in the mouse caecum. Data, normal, $n=5$; tumor, $n=5$. Scale bar, $50 \mu m$. j Kaplan-Meier survival analysis of CRC patients with low and high expression of COL1 mRNA or COL3 mRNA in the human CRC microarray profile GSE39582. Data, $n=566$. $\mathbf{k}$ Schematic diagram of the contribution of tumor bud-derived CCL5 to the TME at the invasive front. ns, no significance; ${ }^{*}, P<0.05 ;{ }^{* *}, P<0.01 ;{ }^{* * *}, P<0.001$ by Mann-Whitney $U$ test $(\mathbf{c}, \mathbf{e})$, Spearman's correlation test $(\mathbf{d}, \mathbf{f}, \mathbf{h})$, log-rank test $(\mathbf{j})$
} 
A

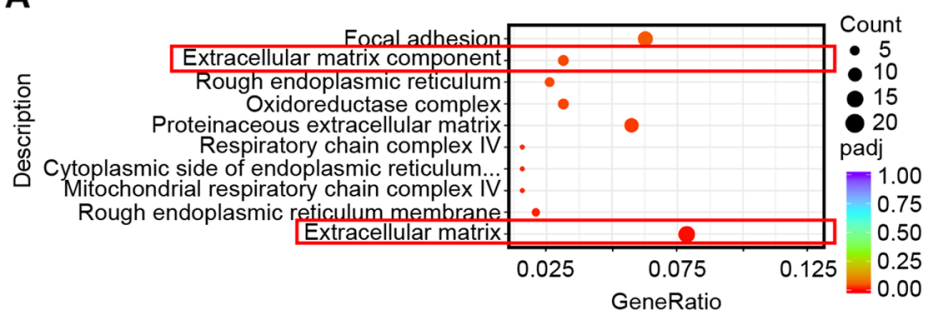

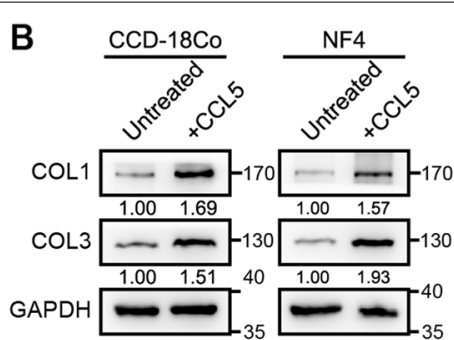
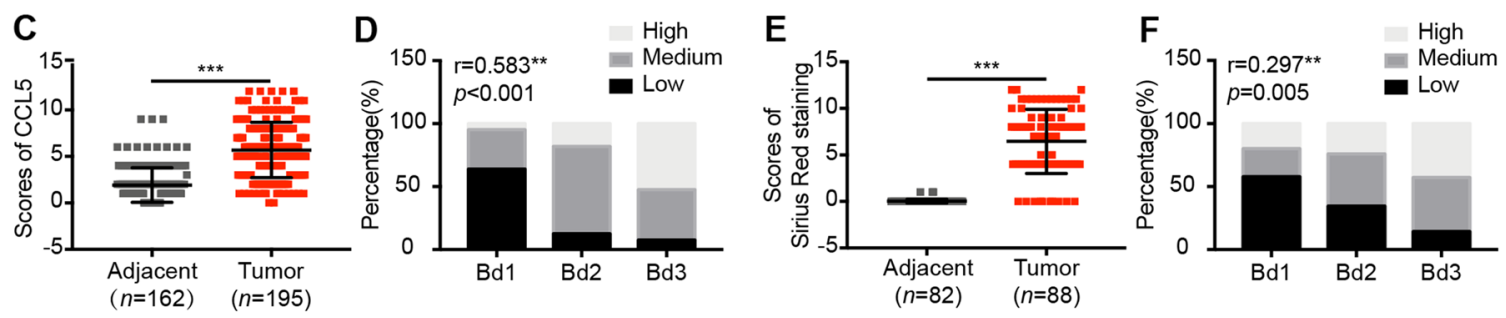

G $\quad \frac{\text { Tumor invasive front(without tumor budding) }}{\mathrm{H} \& \mathrm{E}}$ Sirius Red
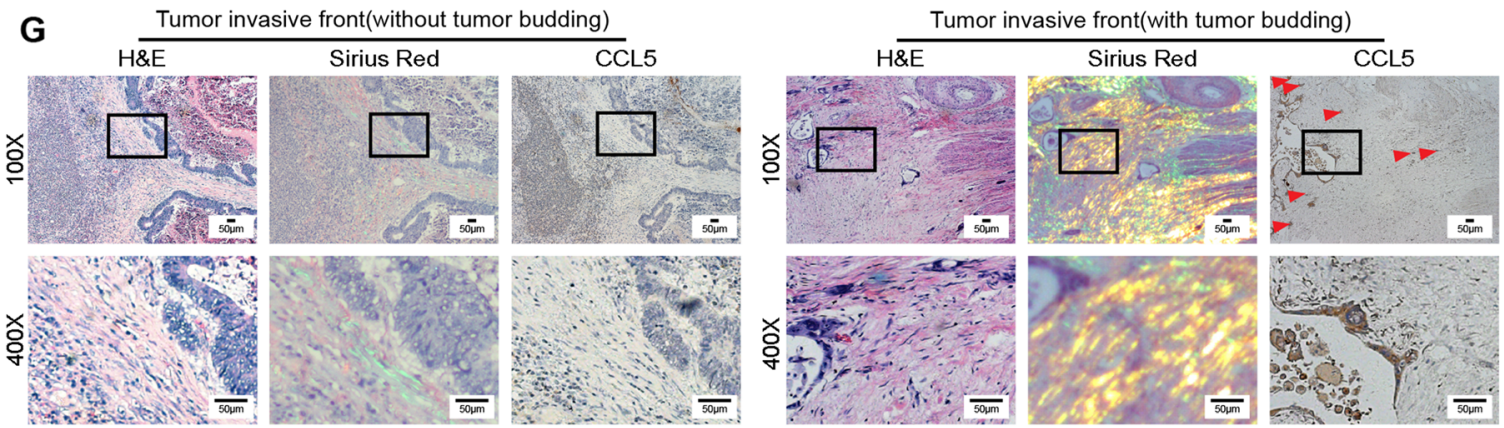

H
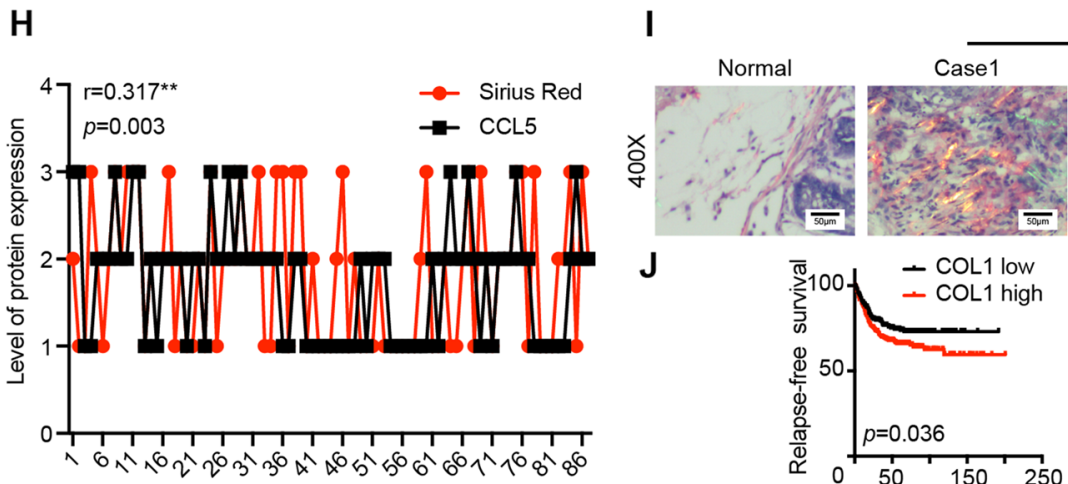

HCT116 Caecum
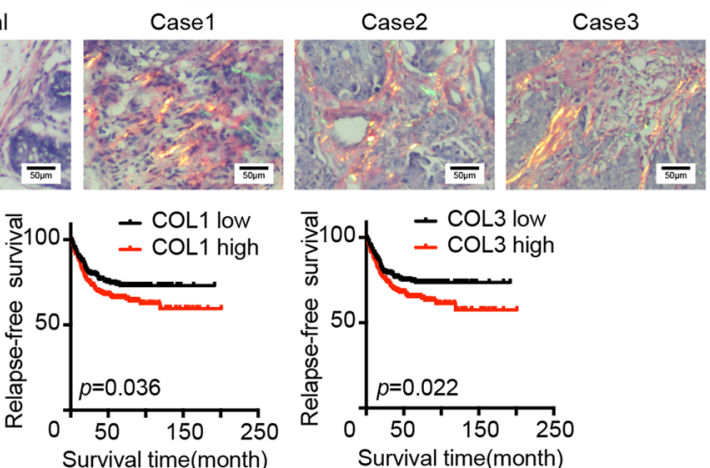

J

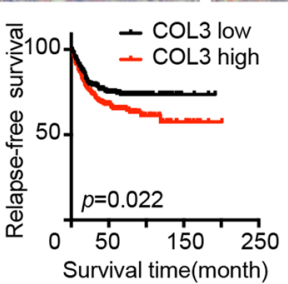

K

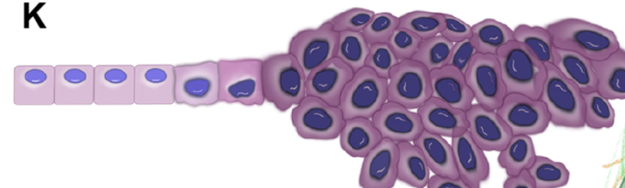

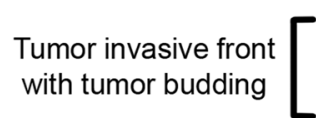
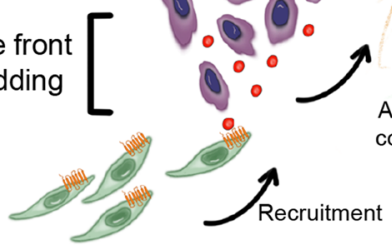

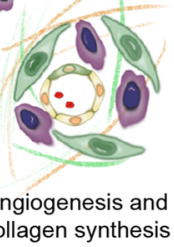

Angiogenesis and llagen synthesis

\section{t}

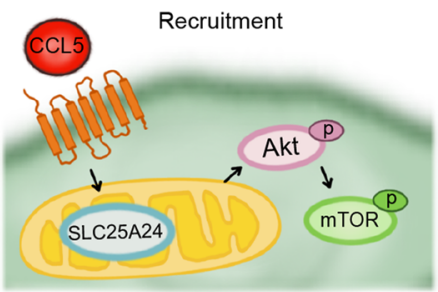

- CCL5

iniiin CCR5

(C) Tumor cell

Fibroblast

Endothelial cell

Collagen 
Table 1 The relationship between CCL5 expression and CRC clinicopathological features

\begin{tabular}{|c|c|c|c|c|c|c|}
\hline & No. of cases & Low & Medium & High & $x^{2}$ value & $P$-value \\
\hline Frequency & $195(100 \%)$ & $65(33.3 \%)$ & $92(47.2 \%)$ & $38(19.5 \%)$ & & \\
\hline \multicolumn{7}{|l|}{ Age } \\
\hline$<60$ years & $96(49.2 \%)$ & $33(34.4 \%)$ & $40(41.7 \%)$ & $23(24.0 \%)$ & \multirow[t]{2}{*}{3.219} & \multirow[t]{2}{*}{0.200} \\
\hline$>=60$ years & $99(50.8 \%)$ & $32(32.3 \%)$ & $52(52.5 \%)$ & $15(15.2 \%)$ & & \\
\hline \multicolumn{7}{|l|}{ Gender } \\
\hline Male & $119(61.0 \%)$ & $43(36.1 \%)$ & $50(42.0 \%)$ & $26(21.8 \%)$ & \multirow[t]{2}{*}{3.317} & \multirow[t]{2}{*}{0.190} \\
\hline Female & $76(39.0 \%)$ & $22(28.9 \%)$ & $42(55.3 \%)$ & $12(15.8 \%)$ & & \\
\hline \multicolumn{7}{|l|}{ Position } \\
\hline Colon & $128(65.6 \%)$ & 41 (32.0\%) & $61(47.7 \%)$ & $26(20.3 \%)$ & \multirow[t]{3}{*}{2.471} & \multirow[t]{3}{*}{0.650} \\
\hline Rectum & $58(29.7 \%)$ & $20(34.5)$ & $26(44.8 \%)$ & $12(20.7 \%)$ & & \\
\hline Colorectum & $9(4.6 \%)$ & $4(44.4 \%)$ & $5(55.6 \%)$ & $0(0.0 \%)$ & & \\
\hline \multicolumn{7}{|c|}{ Tumor size(maximum diameter) } \\
\hline$<5 \mathrm{~cm}$ & $99(51.0 \%)$ & $30(30.3 \%)$ & $52(52.5 \%)$ & $17(17.2 \%)$ & \multirow[t]{2}{*}{2.155} & \multirow[t]{2}{*}{0.340} \\
\hline$>=5 \mathrm{~cm}$ & 95 (49.0\%) & $34(35.8 \%)$ & $40(42.1 \%)$ & $21(22.1 \%)$ & & \\
\hline \multicolumn{7}{|l|}{ Histology } \\
\hline Poor & $22(11.3 \%)$ & $6(27.3 \%)$ & 13 (59.1\%) & $3(13.6 \%)$ & \multirow[t]{3}{*}{1.505} & \multirow[t]{3}{*}{0.826} \\
\hline Moderate & 155 (79.5\%) & $53(34.2 \%)$ & $71(45.8 \%)$ & $31(20.0 \%)$ & & \\
\hline Well & $18(9.2 \%)$ & $6(33.3 \%)$ & $8(44.4 \%)$ & $4(22.2 \%)$ & & \\
\hline \multicolumn{7}{|l|}{ T stage } \\
\hline Tis & $2(1.0 \%)$ & $2(100.0 \%)$ & $0(0.0 \%)$ & $0(0.0 \%)$ & \multirow[t]{5}{*}{22.460} & \multirow[t]{5}{*}{0.004} \\
\hline T1 & $4(2.1 \%)$ & $3(75.0 \%)$ & $1(25.0 \%)$ & $0(0.0 \%)$ & & \\
\hline $\mathrm{T} 2$ & $21(10.8 \%)$ & $6(28.6 \%)$ & $11(52.4 \%)$ & $4(19.0 \%)$ & & \\
\hline T3 & $123(63.1 \%)$ & 47 (38.2\%) & $59(48.0 \%)$ & $17(13.8 \%)$ & & \\
\hline T4 & 45 (23.1\%) & $7(15.6 \%)$ & $21(46.7 \%)$ & $17(37.8 \%)$ & & \\
\hline \multicolumn{7}{|l|}{ Tumor budding } \\
\hline $\mathrm{Bd} 1$ & $83(42.6 \%)$ & 53 (63.9\%) & $26(31.3 \%)$ & $4(4.8 \%)$ & \multirow[t]{3}{*}{84.614} & \multirow[t]{3}{*}{$<0.001$} \\
\hline $\mathrm{Bd} 2$ & 72 (36.9\%) & $9(12.5 \%)$ & $50(69.4 \%)$ & $13(18.1 \%)$ & & \\
\hline $\mathrm{Bd} 3$ & $40(20.5 \%)$ & $3(7.5 \%)$ & $16(40.0 \%)$ & $21(52.5 \%)$ & & \\
\hline Lymphatic meta & & & & & & \\
\hline Negative & $107(54.9 \%)$ & $46(43.0 \%)$ & $46(43.0 \%)$ & $15(14.0 \%)$ & 11.154 & 0.004 \\
\hline Positive & 88 (45.1\%) & $19(21.6 \%)$ & $46(52.3 \%)$ & $23(26.1 \%)$ & & \\
\hline Tumor deposits & & & & & & \\
\hline Absent & $171(87.7 \%)$ & 61 (35.7\%) & 82 (48.0\%) & $28(16.4 \%)$ & 9.366 & 0.009 \\
\hline Present & $24(12.3 \%)$ & $4(16.7 \%)$ & $10(41.7 \%)$ & $10(41.7 \%)$ & & \\
\hline Mucinous comp & & & & & & \\
\hline Absent & $162(83.1 \%)$ & $53(32.7 \%)$ & 77 (47.5\%) & $32(19.8 \%)$ & 0.169 & 0.919 \\
\hline Present & $33(16.9 \%)$ & $12(36.4 \%)$ & $15(45.5 \%)$ & $6(18.2 \%)$ & & \\
\hline Distant metasta & & & & & & \\
\hline Negative & $182(93.3 \%)$ & $63(34.6 \%)$ & $83(45.6 \%)$ & $36(19.8 \%)$ & 2.902 & 0.234 \\
\hline Positive & $13(6.7 \%)$ & $2(15.4 \%)$ & $9(69.2 \%)$ & $2(15.4 \%)$ & & \\
\hline Microstatellite $i$ & & & & & & \\
\hline MSS & $161(82.6 \%)$ & 53 (32.9\%) & $74(46.0 \%)$ & $34(21.1 \%)$ & 4.754 & 0.314 \\
\hline MSI-L & $11(5.6 \%)$ & $6(54.5 \%)$ & $5(45.5 \%)$ & $0(0.0 \%)$ & & \\
\hline MSI-H & $23(11.8 \%)$ & $6(26.1 \%)$ & $13(56.5 \%)$ & $4(17.4 \%)$ & & \\
\hline Neoadjuvant ch & apy & & & & & \\
\hline Negative & $186(95.4 \%)$ & $61(32.8 \%)$ & $90(48.4 \%)$ & $35(18.8 \%)$ & 2.523 & 0.283 \\
\hline Positive & $9(4.6 \%)$ & $4(44.4 \%)$ & $2(22.2 \%)$ & $3(33.3 \%)$ & & \\
\hline TNM stage & & & & & & \\
\hline 0 & $2(1.0 \%)$ & $2(100.0 \%)$ & $0(0.0 \%)$ & $0(0.0 \%)$ & 41.890 & $<0.001$ \\
\hline
\end{tabular}


Table 1 (continued)

\begin{tabular}{llllll}
\hline & No. of cases & Low & Medium & High & $\boldsymbol{x}^{2}$ value \\
\hline I & $18(9.2 \%)$ & $8(44.4 \%)$ & $7(38.9 \%)$ & $3(16.7 \%)$ \\
IIA & $12(6.2 \%)$ & $32(45.7 \%)$ & $30(42.9 \%)$ & $8(11.4 \%)$ \\
IIB & $70(35.9 \%)$ & $2(22.2 \%)$ & $4(44.4 \%)$ & $3(33.3 \%)$ \\
IIIA & $4(2.1 \%)$ & $1(25.0 \%)$ & $2(50.0 \%)$ & $1(25.0 \%)$ \\
IIIB & $56(28.7 \%)$ & $15(26.8 \%)$ & $34(60.7 \%)$ & $7(12.5 \%)$ \\
IIIC & $24(12.3 \%)$ & $3(12.5 \%)$ & $7(29.2 \%)$ & $14(58.3 \%)$ \\
IV & $12(6.2 \%)$ & $2(16.7 \%)$ & $8(66.7 \%)$ & $2(16.7 \%)$ \\
\hline
\end{tabular}

for the highly heterogenous and complicated fibroblast population are currently unavailable. The present study revealed that CRC tumor buds secreted high levels of CCL5, which recruited fibroblasts through CCR5SLC25A24 signaling and led to the development of a characteristic fibroblast cluster around tumor buds at the invasive front. This further facilitated tumor angiogenesis and collagen synthesis, promoting malignant progression (Fig. 6k).

Tumor buds consist of the most aggressive subgroups of tumor cells, which play a leading role in tumor invasion [12, 13]. However, unique markers for tumor budding are unavailable, and H\&E staining is not a reliable method for counting tumor buds when tumor cells are difficult to distinguish from reactive mesenchymal cells. In this study, CCL5 was found to be a marker for tumor budding. Moreover, our findings provide concrete new evidence for the tumor-promoting role of tumor budding. Consequently, the findings indicate that the accuracy of the pathological diagnosis of tumor budding in CRC can be increased by examining CCL5 expression. Studies have shown that the high expression of CCL5 in CRC tumor cells can promote their proliferation [45]. The increased secretion of CCL5 from CRC cells can also promote the apoptosis of $\mathrm{CD}^{+} \mathrm{T}$ cells via regulatory $\mathrm{T}$ cells, thereby promoting tumor progression via immunosuppression [22]. Our study provides more comprehensive insights into the role of CCL5 in CRC progression and elucidates the comprehensive tumor-microenvironment interaction network in CRC. These findings show that therapies targeting CCL5 may play a significant role in blocking CRC progression.

In previous studies, circulating tumor cells have been detected along with fibroblasts, and this finding is highly correlated with tumor metastasis [46-48]. These results suggest that fibroblasts are also critical factors in tumor progression. Thus, the heterogeneity of fibroblasts is also worthy of attention. We found that a subgroup of fibroblasts was stimulated by CCL5. These fibroblasts were $\alpha$-SMA ${ }^{\text {high }}$, CD $90^{\text {high }}$, and FAP ${ }^{\text {low }}$, and were mainly located around tumor buds. These cells contributed to multiple tumor-promoting processes, including tumor angiogenesis and collagen synthesis. Thus, our findings reveal new mechanisms underlying the effect of tumor budding on tumor progression. Besides, our study found that tumor budding promoted fibroblast recruitment through the CCR5 receptor during invasion, and this was a vital step for further angiogenesis and collagen synthesis. Another study has also demonstrated that tumor immune cells can be targeted effectively during CRC metastasis through clinical anti-CCR5 therapy [49]. Consequently, CCR5 inhibitors can not only target immune cells but also fibroblasts at the invasive front of $\mathrm{CRC}$, indicating their value in $\mathrm{CRC}$ treatment. The CCR5 inhibitor Maraviroc, is commonly used in the clinical treatment of HIV [50-52], and it could also have benefits for CRC treatment. Nevertheless, further research remains warranted.

The SLC25 carrier family includes 53 members, most of which transport solutes across the inner mitochondrial membrane during various distinct metabolic processes [53]. SLC25A24 belongs to a subgroup of short calcium-binding mitochondrial carriers (SCaMCs) and has four paralogs in mammals: SCaMC-3/SLC25A23, SCaMC-1/SLC25A24, SCaMC-2/SLC25A25, and SCaMC-3-like/SLC25A41 [54-56]. These carriers consist of a C-terminal domain containing six transmembrane helices homologous to mitochondrial carrier proteins, and an $\mathrm{N}$-terminal domain with $\mathrm{Ca}^{2+}$-binding $\mathrm{EF}$ hands that confer $\mathrm{Ca}^{2+}$ sensitivity to the carrier. As a mitochondrial inner membrane protein, SLC25A24 is involved in the uptake and accumulation of adenine nucleotides [57]. In addition, SLC25A24 is also reported to have anti-oxidative effects [58]. In this study, we found that SLC25A24 was highly expressed in fibroblasts surrounding the tumor buds at the invasive front. The specific regulatory interactions between CCR5 and SLC25A24, and the effect of increased 
Table 2 The relationship between Sirius Red staining and CRC clinicopathological features

\begin{tabular}{|c|c|c|c|c|c|c|}
\hline & No. of cases & Low & Medium & High & $x^{2}$ value & $P$-value \\
\hline Frequency & $88(100 \%)$ & $38(43.2 \%)$ & $28(31.8 \%)$ & $22(25 \%)$ & & \\
\hline \multicolumn{7}{|l|}{ Age } \\
\hline$<60$ years & $40(45.5 \%)$ & $16(40.0 \%)$ & $12(30.0 \%)$ & $12(30.0 \%)$ & \multirow[t]{2}{*}{0.981} & \multirow[t]{2}{*}{0.612} \\
\hline$>=60$ years & $48(54.5 \%)$ & $22(45.8 \%)$ & $16(33.3 \%)$ & $10(20.8 \%)$ & & \\
\hline \multicolumn{7}{|l|}{ Gender } \\
\hline Male & $51(58.0 \%)$ & $22(43.1 \%)$ & $17(33.3 \%)$ & $12(23.5 \%)$ & \multirow[t]{2}{*}{0.193} & \multirow[t]{2}{*}{0.908} \\
\hline Female & $37(42.0 \%)$ & $22(43.2 \%)$ & $42(29.7 \%)$ & $12(27.0 \%)$ & & \\
\hline \multicolumn{7}{|l|}{ Position } \\
\hline Colon & $57(64.8 \%)$ & $21(36.8 \%)$ & $20(35.1 \%)$ & $16(28.1 \%)$ & \multirow[t]{3}{*}{4.218} & \multirow[t]{3}{*}{0.377} \\
\hline Rectum & $27(30.7 \%)$ & $15(55.6 \%)$ & $6(22.2 \%)$ & $6(22.2 \%)$ & & \\
\hline Colorectum & $4(4.5 \%)$ & $2(50.0 \%)$ & $2(50.0 \%)$ & $0(0.0 \%)$ & & \\
\hline \multicolumn{7}{|c|}{ Tumor size(maximum diameter) } \\
\hline$<5 \mathrm{~cm}$ & $46(52.3 \%)$ & $17(37.0 \%)$ & $18(39.1 \%)$ & $11(23.9 \%)$ & \multirow[t]{2}{*}{2.530} & \multirow[t]{2}{*}{0.282} \\
\hline$>=5 \mathrm{~cm}$ & $42(47.7 \%)$ & $21(50.0 \%)$ & $10(23.8 \%)$ & $11(26.2 \%)$ & & \\
\hline \multicolumn{7}{|l|}{ Histology } \\
\hline Poor & $13(14.8 \%)$ & $6(46.2 \%)$ & $2(15.4 \%)$ & $5(38.5 \%)$ & \multirow[t]{3}{*}{5.948} & \multirow[t]{3}{*}{0.203} \\
\hline Moderate & $65(73.9 \%)$ & $25(38.5 \%)$ & $24(36.9 \%)$ & 16 (24.6\%) & & \\
\hline Well & $10(11.4 \%)$ & $7(70.0 \%)$ & $2(20.0 \%)$ & $1(10.0 \%)$ & & \\
\hline \multicolumn{7}{|l|}{ T stage } \\
\hline Tis & $1(1.1 \%)$ & $1(100.0 \%)$ & $0(0.0 \%)$ & $0(0.0 \%)$ & \multirow[t]{5}{*}{19.325} & \multirow[t]{5}{*}{0.013} \\
\hline $\mathrm{T} 1$ & $3(3.4 \%)$ & $3(100.0 \%)$ & $0(0.0 \%)$ & $0(0.0 \%)$ & & \\
\hline $\mathrm{T} 2$ & $12(13.6 \%)$ & $10(83.3 \%)$ & $2(16.7 \%)$ & $0(0.0 \%)$ & & \\
\hline T3 & $57(64.8 \%)$ & $21(36.8 \%)$ & $21(36.8 \%)$ & 15 (26.3\%) & & \\
\hline T4 & $15(17.0 \%)$ & $3(20.0 \%)$ & $5(33.3 \%)$ & $7(46.7 \%)$ & & \\
\hline \multicolumn{7}{|l|}{ Tumor budding } \\
\hline $\mathrm{Bd} 1$ & $45(51.1 \%)$ & $26(57.8 \%)$ & $10(22.2 \%)$ & $9(20.0 \%)$ & 10.351 & 0.035 \\
\hline $\mathrm{Bd} 2$ & $29(33.0 \%)$ & $10(34.5 \%)$ & $12(41.4 \%)$ & $7(24.1 \%)$ & & \\
\hline $\mathrm{Bd} 3$ & $14(15.9 \%)$ & $2(14.3 \%)$ & $6(42.9 \%)$ & $6(42.9 \%)$ & & \\
\hline Lymphatic met & & & & & & \\
\hline Negative & $48(54.5 \%)$ & $28(58.3 \%)$ & $13(27.1 \%)$ & $7(14.6 \%)$ & 10.941 & 0.004 \\
\hline Positive & $40(45.5 \%)$ & $10(25.0 \%)$ & $15(37.5 \%)$ & $15(37.5 \%)$ & & \\
\hline Tumor deposits & & & & & & \\
\hline Absent & $75(85.2 \%)$ & $36(48.0 \%)$ & $24(32.0 \%)$ & $15(20.0 \%)$ & 7.812 & 0.020 \\
\hline Present & $13(14.8 \%)$ & $2(15.4 \%)$ & $4(30.8 \%)$ & $7(53.8 \%)$ & & \\
\hline Mucinous coml & & & & & & \\
\hline Absent & $17(19.3 \%)$ & $7(41.2 \%)$ & $5(29.4 \%)$ & $5(29.4 \%)$ & 0.222 & 0.895 \\
\hline Present & $71(80.7 \%)$ & $31(43.7 \%)$ & $23(32.4 \%)$ & $17(23.9 \%)$ & & \\
\hline Distant metast & & & & & & \\
\hline Negative & $85(96.6 \%)$ & $37(43.5 \%)$ & $27(31.8 \%)$ & $21(24.7 \%)$ & 0.158 & 0.924 \\
\hline Positive & $3(3.4 \%)$ & $1(33.3 \%)$ & $1(33.3 \%)$ & $1(33.3 \%)$ & & \\
\hline Microstatellite & & & & & & \\
\hline MSS & $71(80.7 \%)$ & $28(39.4 \%)$ & $24(33.8 \%)$ & $19(26.8 \%)$ & 4.258 & 0.372 \\
\hline MSI-L & $7(8.0 \%)$ & $3(42.9 \%)$ & $3(42.9 \%)$ & $1(14.3 \%)$ & & \\
\hline MSI-H & $10(11.4 \%)$ & $7(70.0 \%)$ & $1(10.0 \%)$ & $2(20.0 \%)$ & & \\
\hline Neoadjuvant cl & & & & & & \\
\hline Negative & $87(98.9 \%)$ & $38(32.8 \%)$ & $28(48.4 \%)$ & $21(18.8 \%)$ & 3.034 & 0.219 \\
\hline Positive & $1(1.1 \%)$ & $0(44.4 \%)$ & $0(22.2 \%)$ & $1(33.3 \%)$ & & \\
\hline TNM stage & & & & & & \\
\hline 0 & $2(2.3 \%)$ & $2(100.0 \%)$ & $0(0.0 \%)$ & $0(0.0 \%)$ & 20.396 & 0.009 \\
\hline 1 & $10(11.4 \%)$ & $9(90.0 \%)$ & $1(10.0 \%)$ & $0(0.0 \%)$ & & \\
\hline$\|$ & $31(35.2 \%)$ & $16(51.6 \%)$ & $10(32.3 \%)$ & $5(16.1 \%)$ & & \\
\hline III & $42(47.7 \%)$ & $10(23.8 \%)$ & $16(38.1 \%)$ & 16 (38.1\%) & & \\
\hline IV & $3(3.4 \%)$ & 1 (33.3\%) & $1(33.3 \%)$ & $1(33.3 \%)$ & & \\
\hline
\end{tabular}


SLC25A24 expression on mitochondrial function still require further researches. Further, the effect of these SLC25A24 ${ }^{\text {high }}$ fibroblasts on tumor cells is still unclear and remains to be understood.

\section{Conclusions}

In conclusion, the present study suggests that at the invasive front of CRC, tumor bud-derived CCL5 can recruit fibroblasts via CCR5-SLC25A24 signaling. Accordingly, tumor bud-derived CCL5 can further promote angiogenesis and collagen synthesis through fibroblasts, and eventually, create a tumor-promoting microenvironment. Therefore, our study provides evidences indicating that CCL5 may serve as a potential diagnostic marker and therapeutic target for tumor budding in CRC.

\begin{abstract}
Abbreviations
CRC: Colorectal cancer; CCL5: C-C chemokine ligand 5; SLC25A24: Solute carrier family 25 member 24; TME: Tumor microenvironment; CAFs: Cancer-associated fibroblasts; RANTES: Regulated upon Activation, Normal T-cell Expressed, and Secreted; siRNA: Small interfering RNA; shRNA: Short hairpin RNA; ATCC: American Type Culture Collection; FBS: Fetal bovine serum; EMEM: Eagle's Minimum Essential Medium; ITBCC: International Tumor Budding Consensus Conference; IHC: Immunohistochemistry; IF: Immunofluorescence; ELISA: Enzyme-linked immunosorbent assay; qRT-PCR: Quantitative reverse transcription polymerase chain reaction; CM: Conditioned medium; SDS-PAGE: Sodium dodecyl sulfate-polyacrylamide gel electrophoresis; PVDF: Polyvinylidene fluoride; H\&E: Hematoxylin-eosin; Flow-Cyt: Flow cytometry; COL1: Collagen type I; COL3: Collagen type III; APC1: ATP-Mg ${ }^{2+}$ / phosphate carrier 1; SCaMCs: Short calcium-binding mitochondrial carriers.
\end{abstract}

\section{Supplementary Information}

The online version contains supplementary material available at https://doi. org/10.1186/s13046-022-02300-w.

Additional file 1: Figure S1. Extraction and verification of human primary normal colorectal fibroblasts.

Additional file 2: Figure S2. CRC tumor cells in tumor buds recruit fibroblasts via CCL5.

Additional file 3: Figure S3. CCL5-dependent fibroblast recruitment is mediated by SLC25A24 in fibroblasts.

Additional file 4: Figure S4. CCL5 contributes to the increase in a-SMA high $C D 90^{\text {high }}$ FAPlow fibroblasts and thereby promotes tumor angiogenesis.

Additional file 5: Figure S5. CCL5 promotes collagen synthesis via fibroblasts, contributing to tumor progression.

Additional file 6: Table S1. List of primary antibodies used in the study. Additional file 7: Table S2. List of RNA interference oligo sequences. Additional file 8: Table S3. List of primer sequences.

\section{Acknowledgements}

The authors would like to thank all the reviewers who participated in the review, as well as MJEditor (www.mjeditor.com) for providing English editing services during the preparation of this manuscript.

\section{Authors' contributions}

Zu-Guo Li, Xiao-Yan Wang and Zhi-Yan Hu conceived and designed the study. Ling-Fang Gao, Xia Wang and Jia-Xian Zhu performed the experiments. Ling-Fang Gao interpreted and analyzed the data. Ling-Fang Gao and Yan Zhong wrote and reviewed the manuscript. Ling-Fang Gao and Ting Long prepared figures. All authors read and approved the final manuscript.

\section{Funding}

This study was funded by the National Natural Science Foundation of China (No. 81974441) and the Science and Technology Planning Project of Shenzhen Municipality (JCYJ20190814105619048).

\section{Availability of data and materials}

All data presented or analyzed in this study are included either in this article or in the additional files.

\section{Declarations}

\section{Ethics approval and consent to participate}

This study was approved by the ethics committee of Shenzhen Hospital, Southern Medical University, China.

\section{Consent for publication}

All authors have consented to the publication of the results presented in this manuscript.

\section{Competing interests}

The authors have no conflicts of interest to declare.

\section{Author details}

'Department of Pathology, Shenzhen Hospital, Southern Medical University, Shenzhen 518101, Guangdong, China. ${ }^{2}$ Department of Pathology, School of Basic Medical Sciences, Southern Medical University, Guangzhou 510515, Guangdong, China. ${ }^{3}$ Department of Pathology, Nanfang Hospital, Southern Medical University, Guangzhou 510515, Guangdong, China.

Received: 13 October 2021 Accepted: 25 February 2022 Published online: 03 March 2022

\section{References}

1. Kalluri R. The biology and function of fibroblasts in cancer. Nat Rev Cancer. 2016;16:582-98.

2. Kalluri R, Zeisberg M. Fibroblasts in cancer. Nat Rev Cancer. 2006;6:392-401.

3. Kuzet SE, Gaggioli C. Fibroblast activation in cancer: when seed fertilizes soil. Cell Tissue Res. 2016;365:607-19.

4. Su S, Chen J, Yao H, Liu J, Yu S, Lao L, Wang M, Luo M, Xing Y, Chen F, et al. CD10(+)GPR77(+) Cancer-Associated Fibroblasts Promote Cancer Formation and Chemoresistance by Sustaining Cancer Stemness. Cell. 2018;172:841-856 e816.

5. Murata T, Mizushima H, Chinen I, Moribe H, Yagi S, Hoffman RM, Kimura T, Yoshino K, Ueda Y, Enomoto T, et al. HB-EGF and PDGF mediate reciprocal interactions of carcinoma cells with cancer-associated fibroblasts to support progression of uterine cervical cancers. Cancer Res. 2011;71:6633-42.

6. Chen WJ, Ho CC, Chang YL, Chen HY, Lin CA, Ling TY, Yu SL, Yuan SS, Chen YJ, Lin CY, et al. Cancer-associated fibroblasts regulate the plasticity of lung cancer stemness via paracrine signalling. Nat Commun. 2014;5:3472.

7. Cadamuro M, Nardo G, Indraccolo S, Dall'olmo L, Sambado L, Moserle L, Franceschet I, Colledan M, Massani M, Stecca T, et al. Platelet-derived growth factor-D and Rho GTPases regulate recruitment of cancer-associated fibroblasts in cholangiocarcinoma. Hepatology. 2013;58:1042-53.

8. Heichler C, Scheibe K, Schmied A, Geppert Cl, Schmid B, Wirtz S, Thoma OM, Kramer V, Waldner MJ, Buttner C, et al. STAT3 activation through IL-6/L-11 in cancer-associated fibroblasts promotes colorectal tumour development and correlates with poor prognosis. Gut. 2020;69:1269-82.

9. Hu JL, Wang W, Lan XL, Zeng ZC, Liang YS, Yan YR, Song FY, Wang FF, Zhu XH, Liao WJ, et al. CAFs secreted exosomes promote metastasis and chemotherapy resistance by enhancing cell stemness and epithelialmesenchymal transition in colorectal cancer. Mol Cancer. 2019;18:91. 
10. Huelsken J, Hanahan D. A Subset of Cancer-Associated Fibroblasts Determines Therapy Resistance. Cell. 2018;172:643-4.

11. Elyada E, Bolisetty M, Laise P, Flynn WF, Courtois ET, Burkhart RA, Teinor JA, Belleau P, Biffi G, Lucito MS, et al. Cross-Species Single-Cell Analysis of Pancreatic Ductal Adenocarcinoma Reveals Antigen-Presenting Cancer-Associated Fibroblasts. Cancer Discov. 2019;9:1102-23.

12. Dawson H, Galuppini F, Trager P, Berger MD, Studer P, Brugger L, Zlobec I, Inderbitzin D, Lugli A. Validation of the International Tumor Budding Consensus Conference 2016 recommendations on tumor budding in stage I-IV colorectal cancer. Hum Pathol. 2019;85:145-51.

13. Lugli A, Kirsch R, Ajioka Y, Bosman F, Cathomas G, Dawson H, El Zimaity H, Flejou JF, Hansen TP, Hartmann A, et al. Recommendations for reporting tumor budding in colorectal cancer based on the International Tumor Budding Consensus Conference (ITBCC) 2016. Mod Pathol. 2017;30:1299-311.

14. Zhang N, Wang D, Duan Y, Ayarick VA, Cao M, Wang Y, Zhang G, Wang $Y$. The special immune microenvironment of tumor budding and its impact on prognosis in gastric adenocarcinoma. Pathol Res Pract. 2020;216:152926.

15. Kadota K, Yeh YC, Villena-Vargas J, Cherkassky L, Drill EN, Sima CS, Jones DR, Travis WD, Adusumilli PS. Tumor Budding Correlates With the Protumor Immune Microenvironment and Is an Independent Prognostic Factor for Recurrence of Stage I Lung Adenocarcinoma. Chest. 2015;148:711-21.

16. Wartenberg M, Cibin S, Zlobec I, Vassella E, Eppenberger-Castori S, Terracciano L, Eichmann MD, Worni M, Gloor B, Perren A, et al. Integrated Genomic and Immunophenotypic Classification of Pancreatic Cancer Reveals Three Distinct Subtypes with Prognostic/Predictive Significance. Clin Cancer Res. 2018;24:4444-54.

17. Guil-Luna S, Mena R, Navarrete-Sirvent C, Lopez-Sanchez LM, Khouadri K, Toledano-Fonseca M, Mantrana A, Guler I, Villar C, Diaz C, et al. Association of Tumor Budding With Immune Evasion Pathways in Primary Colorectal Cancer and Patient-Derived Xenografts. Front Med (Lausanne). 2020;7:264.

18. Dedoni S, Campbell LA, Harvey BK, Avdoshina V, Mocchetti I. The orphan G-protein-coupled receptor 75 signaling is activated by the chemokine CCL5. J Neurochem. 2018;146:526-39.

19. Aldinucci D, Colombatti A. The inflammatory chemokine CCL5 and cancer progression. Mediators Inflamm. 2014;2014:292376.

20. Aldinucci D, Borghese C, Casagrande N. The CCL5/CCR5 Axis in Cancer Progression. Cancers. 2020;12:1765.

21. Liu C, Yao ZY, Wang JN, Zhang W, Yang Y, Zhang Y, Qu XL, Zhu YB, Zou $\mathrm{J}$, Peng SS, et al. Macrophage-derived CCL5 facilitates immune escape of colorectal cancer cells via the p65/STAT3-CSN5-PD-L1 pathway. Cell Death Differ. 2020;27:1765-81.

22. Chang LY, Lin YC, Mahalingam J, Huang CT, Chen TW, Kang CW, Peng HM, Chu YY, Chiang JM, Dutta A, et al. Tumor-Derived Chemokine CCL5 Enhances TGF-beta-Mediated Killing of CD8(+) T Cells in Colon Cancer by T-Regulatory Cells. Can Res. 2012;72:1092-102.

23. Eyman D, Damodarasamy M, Plymate SR, Reed MJ. CCL5 secreted by senescent aged fibroblasts induces proliferation of prostate epithelial cells and expression of genes that modulate angiogenesis. J Cell Physiol. 2009;220:376-81.

24. Nakamura K, Kiniwa Y, Okuyama R. CCL5 production by fibroblasts through a local renin-angiotensin system in malignant melanoma affects tumor immune responses. J Cancer Res Clin Oncol. 2021:147:1993-2001.

25. Sun X, Chen Z. Cancer-associated fibroblast-derived CCL5 contributes to cisplatin resistance in A549 NSCLC cells partially through upregulation of IncRNA HOTAIR expression. Oncol Lett. 2021;22:696.

26. Hu Z, Long T, Ma Y, Zhu J, Gao L, Zhong Y, Wang X, Wang X, Li Z. Correction to: Downregulation of GLYR1 contributes to microsatellite instability colorectal cancer by targeting p21 via the p38MAPK and PI3K/AKT pathways. J Exp Clin Cancer Res. 2020;39:125.

27. De Vincenzo A, Belli S, Franco P, Telesca M, laccarino I, Botti G, Carriero MV, Ranson M, Stoppelli MP. Paracrine recruitment and activation of fibroblasts by c-Myc expressing breast epithelial cells through the IGFs/IGF-1R axis. Int J Cancer. 2019;145:2827-39.

28. Sasaki S, Baba T, Shinagawa K, Matsushima K, Mukaida N. Crucial involvement of the CCL3-CCR5 axis-mediated fibroblast accumulation in colitisassociated carcinogenesis in mice. Int J Cancer. 2014;135:1297-306.
29. Tanabe Y, Sasaki S, Mukaida N, Baba T. Blockade of the chemokine receptor, CCR5, reduces the growth of orthotopically injected colon cancer cells via limiting cancer-associated fibroblast accumulation. Oncotarget. 2016;7:48335-45.

30. Fiermonte G, De Leonardis F, Todisco S, Palmieri L, Lasorsa FM, Palmieri F. Identification of the human mitochondrial ATP-Mg/Pi transporter. BbaBioenergetics. 2004;1658:191-191.

31. Harborne SPD, Ruprecht JJ, Kunji ERS. Calcium-induced conformational changes in the regulatory domain of the human mitochondrial ATP-Mg/Pi carrier. Bba-Bioenergetics. 2015;1847:1245-53.

32. Monne M, Daddabbo L, Giannossa LC, Nicolardi MC, Palmieri L, Miniero DV, Mangone A, Palmieri F. Mitochondrial ATP-Mg/phosphate carriers transport divalent inorganic cations in complex with ATP. J Bioenerg Biomembr. 2017:49:369-80.

33. Claesson-Welsh L, Welsh M. VEGFA and tumour angiogenesis. J Intern Med. 2013;273:114-27.

34. Frangogiannis NG. Fact and Fiction About Fibroblast to Endothelium Conversion Semantics and Substance of Cellular Identity. Circulation. 2020;142:1663-6.

35. Han JK, Chang SH, Cho HJ, Choi SB, Ahn HS, Lee J, Jeong H, Youn SW, Lee $\mathrm{HJ}$, Kwon YW, et al. Direct conversion of adult skin fibroblasts to endothelial cells by defined factors. Circulation. 2014;130:1168-78.

36. Kurian L, Sancho-Martinez I, Nivet E, Aguirre A, Moon K, Pendaries C, Volle-Challier C, Bono F, Herbert JM, Pulecio J, et al. Conversion of human fibroblasts to angioblast-like progenitor cells. Nat Methods. 2013;10:77-83.

37. Jia H, Janjanam J, Wu SC, Wang R, Pano G, Celestine M, Martinot O, BreezeJones H, Clayton G, Garcin C, et al. The tumor cell-secreted matricellular protein WISP1 drives pro-metastatic collagen linearization. EMBO J. 2019;38:e101302.

38. Levental KR, Yu H, Kass L, Lakins JN, Egeblad M, Erler JT, Fong SF, Csiszar K, Giaccia A, Weninger W, et al. Matrix crosslinking forces tumor progression by enhancing integrin signaling. Cell. 2009;139:891-906.

39. Hanahan D, Weinberg RA. The hallmarks of cancer. Cell. 2000;100:57-70.

40. Hanahan D, Weinberg RA. Hallmarks of cancer: the next generation. Cell. 2011;144:646-74.

41. Isella C, Terrasi A, Bellomo SE, Petti C, Galatola G, Muratore A, Mellano A, Senetta R, Cassenti A, Sonetto C, et al. Stromal contribution to the colorectal cancer transcriptome. Nat Genet. 2015;47:312-9.

42. Kasashima H, Duran A, Martinez-Ordonez A, Nakanishi Y, Kinoshita H, Linares JF, Reina-Campos M, Kudo Y, L'Hermitte A, Yashiro M, et al. Stromal SOX2 Upregulation Promotes Tumorigenesis through the Generation of a SFRP1/2-Expressing Cancer-Associated Fibroblast Population. Dev Cell. 2021;56:95.

43. Wang W, Tang YA, Xiao Q, Lee WC, Cheng B, Niu Z, Oguz G, Feng M, Lee PL, $\mathrm{Li} B$, et al. Stromal induction of BRD4 phosphorylation Results in Chromatin Remodeling and BET inhibitor Resistance in Colorectal Cancer. Nat Commun. 2021;12:4441.

44. Yu M, Guo G, Huang L, Deng L, Chang CS, Achyut BR, Canning M, Xu N, Arbab AS, Bollag RJ, et al. CD73 on cancer-associated fibroblasts enhanced by the A2B-mediated feedforward circuit enforces an immune checkpoint. Nat Commun. 2020;11:515.

45. Niu MK, Yi M, Dong B, Luo SX, Wu KM. Upregulation of STAT1-CCL5 axis is a biomarker of colon cancer and promotes the proliferation of colon cancer cells. Annals of Translational Medicine. 2020;8:951.

46. Ao Z, Shah SH, Machlin LM, Parajuli R, Miller PC, Rawal S, Williams AJ, Cote RJ, Lippman ME, Datar RH, et al. Identification of Cancer-Associated Fibroblasts in Circulating Blood from Patients with Metastatic Breast Cancer. Cancer Res. 2015;75:4681-7.

47. Duda DG, Duyverman AMMJ, Kohno M, Snuderl M, Steller EJA, Fukumura D, Jain RK. Malignant cells facilitate lung metastasis by bringing their own soil. P Natl Acad Sci USA. 2010;107:21677-82.

48. Jones ML, Siddiqui J, Pienta KJ, Getzenberg RH. Circulating fibroblast-like cells in men with metastatic prostate cancer. Prostate. 2013;73:176-81.

49. Halama N, Zoernig I, Berthel A, Kahlert C, Klupp F, Suarez-Carmona M, Suetterlin T, Brand K, Krauss J, Lasitschka F, et al. Tumoral Immune Cell Exploitation in Colorectal Cancer Metastases Can Be Targeted Effectively by Anti-CCR5 Therapy in Cancer Patients. Cancer Cell. 2016;29:587-601.

50. Gulick RM, Wilkin TJ, Chen YQ, Landovitz RJ, Amico KR, Young AM, Richardson P, Marzinke MA, Hendrix CW, Eshleman SH, et al. Safety and Tolerability of Maraviroc-Containing Regimens to Prevent HIV Infection in Women: A Phase 2 Randomized Trial. Ann Intern Med. 2017;167:384-93. 
51. Levy Y, Lelievre JD, Assoumou L, Aznar E, Pulido F, Tambussi G, Crespo M, Meybeck A, Molina JM, Delaugerre C, et al. Addition of Maraviroc Versus Placebo to Standard Antiretroviral Therapy for Initial Treatment of Advanced HIV Infection: A Randomized Trial. Ann Intern Med. 2020;172:297-305.

52. Tan Q, Zhu Y, Li J, Chen Z, Han GW, Kufareva I, Li T, Ma L, Fenalti G, Li J, et al. Structure of the CCR5 chemokine receptor-HIV entry inhibitor maraviroc complex. Science. 2013;341:1387-90.

53. Cunningham CN, Rutter J. 20,000 picometers under the OMM: diving into the vastness of mitochondrial metabolite transport. EMBO Rep. 2020;21:e50071.

54. del Arco A, Satrustegui J. Identification of a novel human subfamily of mitochondrial carriers with calcium-binding domains. J Biol Chem. 2004;279:24701-13.

55 Fiermonte G, De Leonardis F, Todisco S, Palmieri L, Lasorsa FM, Palmieri F. Identification of the mitochondrial ATP-Mg/Pi transporter. Bacterial expression, reconstitution, functional characterization, and tissue distribution. J Biol Chem. 2004;279:30722-30

56. Traba J, Satrustegui J, del Arco A. Characterization of SCaMC-3-like/slc25a41, a novel calcium-independent mitochondrial ATP-Mg/Pi carrier. Biochem J. 2009:418:125-33.

57. Aprille JR. Regulation of the mitochondrial adenine nucleotide pool size in liver: mechanism and metabolic role. FASEB J. 1988;2:2547-56.

58. Traba J, Del Arco A, Duchen MR, Szabadkai G, Satrustegui J. SCaMC-1 promotes cancer cell survival by desensitizing mitochondrial permeability transition via ATP/ADP-mediated matrix $\mathrm{Ca}(2+)$ buffering. Cell Death Differ. 2012;19:650-60

\section{Publisher's Note}

Springer Nature remains neutral with regard to jurisdictional claims in published maps and institutional affiliations.

- fast, convenient online submission

- thorough peer review by experienced researchers in your field

- rapid publication on acceptance

- support for research data, including large and complex data types

- gold Open Access which fosters wider collaboration and increased citations

- maximum visibility for your research: over $100 \mathrm{M}$ website views per year

At BMC, research is always in progress.

Learn more biomedcentral.com/submissions 